\title{
Numerical Simulation of a Simplified High-Lift CRM Configuration Embedded with Fluidic Actuators
}

\author{
Veer N. Vatsa* \\ NASA Langley Research Center, Hampton, VA 23681
}

Benjamin Duda ${ }^{\dagger}$

Exa GmbH, Landshuter Allee 8, 80637 Munich, Germany

\author{
John C. Lin,$^{\ddagger}$ Latunia P. Melton ${ }^{\ddagger}$ and Matthew O’Connell ${ }^{\S}$
}

NASA Langley Research Center, Hampton, VA 23681

\begin{abstract}
Numerical simulations have been performed for a simplified high-lift configuration that is representative of a modern transport airplane. This configuration includes a leading-edge slat, fuselage, wing, nacelle-pylon and a simple hinged flap. The suction surface of the flap is embedded with multiple rows of fluidic actuators to reduce the extent of reversed flow regions and improve the aerodynamic performance of the configuration with flap in a deployed state. In the current paper, a Lattice Boltzmann Method based high-fidelity computational fluid dynamics (CFD) code, known as PowerFLOW ${ }^{\circledR}$ is used to simulate the entire flow field associated with this configuration, including the flow inside the actuators. A fully compressible version of the PowerFLOW ${ }^{\circledR}$ code $^{\circ}$ that has been validated for high speed flows is used for the present simulations to accurately represent the transonic flow regimes that are encountered in the flow field generated by the actuators operating at higher mass flow (momentum) rates required to mitigate reverse flow regions on the suction surfaces of the main wing and the flap. The numerical solutions predict the expected trends in aerodynamic forces as the actuation levels are increased. More efficient active flow control (AFC) systems and actuator arrangement for lift augmentation are emerging based on the parametric studies conducted here prior to wind tunnel tests. These numerical solutions will be compared with experimental data, once such data becomes available.
\end{abstract}

* Senior Research Scientist, Computational AeroSciences Branch, Research Directorate; Associate Fellow AIAA

${ }^{\dagger}$ Senior Application Engineer, Aerospace

${ }_{\ddagger}^{\ddagger}$ Senior Research Scientist, Flow Physics Branch, Research Directorate; Associate Fellow AIAA

$\S$ Research Engineer, Computational AeroSciences Branch, Research Directorate; Member AIAA 


\section{Nomenclature}

\begin{tabular}{ll} 
AATT & Advanced Air Transport Technology \\
AFC & active flow control \\
$A_{r e f}$ & total projected area of wing in cruise configuration \\
CFD & computational fluid dynamics \\
CRM & Common Research Model \\
$C_{L}$ & lift coefficient $F_{z} /\left(0.5 \rho_{\infty} V_{\infty}^{2} A_{r e f}\right)$ \\
$C_{p}$ & pressure coefficient, $\left(p-p_{\infty}\right) /\left(0.5 \rho_{\infty} V_{\infty}{ }^{2}\right)$ \\
c & chord \\
DNS & direct numerical simulation \\
$F_{z}$ & $z$-component of integrated force \\
HL & high lift \\
IB & inboard \\
LBM & Lattice Boltzmann Method \\
lb & pound mass \\
M & Mach number \\
mac & mean aerodynamic chord \\
mdot & total mass flow through actuators \\
NASA & National Aeronautics and Space Administration \\
OB & outboard \\
P & pressure ratio at feed tube \\
$p$ & static pressure \\
psd & power spectral density \\
SHL & simplified high lift \\
$V$ & total velocity \\
VLES & very large eddy simulation \\
VR & variable resolution regions \\
$3-D$ & three-dimensional \\
$u, v, w$ & Cartesian fluid velocity components \\
$x, y, z$ & Cartesian coordinates \\
$\rho$ & density \\
Superscript: & \\
\hline & \\
& \\
&
\end{tabular}

\section{Introduction}

The high-lift systems of modern transport aircraft are strongly influencing the sizing, economics, and safety of the aircraft design. ${ }^{1}$ The NASA Advanced Air Transport Technology (AATT) Project is seeking to demonstrate the potential benefits of reducing the cruise drag (and therefore fuel burn) associated with modern high-lift systems without sacrificing aerodynamic and acoustic performance during takeoff and landing operations. One possible approach is to use active flow control (AFC) $)^{2,3}$ to provide the required lift performance while reducing the cruise drag associated with the external mechanisms used to deploy a conventional slotted flap during high-lift operations. ${ }^{4,5}$

A recent system integration study by Hartwich et al. ${ }^{5,6}$ indicated that up to a $2.25 \%$ fuel burn reduction is possible if an AFC-enabled simplified high-lift system (i.e., simple hinged flaps inboard and outboard) could provide the necessary lift recovery at the approach angle of attack. The AFC-related performance gains are primarily due to the 3.3-count excrescence drag reduction from the removal of the external fairings for the Fowler flap mechanism ${ }^{7}$ (see Fig. 1 (left side) for a typical example). However, the main challenge here is to develop an AFC system that can provide the necessary lift recovery for a simple hinged flap high-lift system (Fig. 1 (right side)) while minimizing the pneumatic 
power usage. Pneumatic-powered AFC concepts, such as the steady blowing through discrete convergent-divergent nozzles ${ }^{6}$ or unsteady blowing through fluidic oscillators (often referred as sweeping jet actuators), ${ }^{8-18}$ will be investigated around the flap shoulder region during the course of this project. For the current paper, the effect of placing multiple rows of fluidic actuators on the flap shoulder region will be examined based on experimental evidence from the work of DeSalvo et al. ${ }^{8,9}$ suggesting that multiple rows of AFC actuation on a simple hinged flap high-lift airfoil could be effective at lift enhancement while keeping the momentum coefficient at relatively low levels.

Recent advances in computational fluid dynamics (CFD) methods have made it possible to simulate the effect of AFC devices on major aircraft components, as evidenced by a series of publications in the literature. ${ }^{19-23}$ The current CFD study also leverages the knowledge gained from prior subscale simulations by Vatsa et al. ${ }^{24,25}$ for an AFC-enhanced vertical tail configuration.

In recent years, there were strong desires from government, industry, and academia for an "open" high-lift geometry that is representative of a modern transport aircraft for AFC research as well as R\&D efforts related to noise reduction, high-lift aerodynamics/flow physics, and CFD development/validation. As a result, an open conventional high-lift geometry that is based on the NASA Common Research Model (CRM) ${ }^{26,27}$ was proposed by Lacy and Sclafani. ${ }^{28}$ A $10 \%$-scale high-lift version of the CRM (CRM-HL) based on the geometry of Ref. 28 is being designed and built for wind tunnel testing ${ }^{29}$ at the NASA Langley Research Center 14- by 22 -Foot Subsonic Tunnel $(14 \times 22)$ during calendar year (CY) 2018. A simple hinged flap geometry with integrated and exchangeable AFC modules was derived from the conventional CRM-HL design. This paper will describe the CFD results for the AFC-enabled CRM-HL configurations currently under development, which could lead to subsequent testing at the $14 \times 22$ wind tunnel.

\section{Configuration and Computational Setup}

The configuration under consideration here corresponds to the $10 \%$-scale, semispan model of the AFC-enabled CRM-HL geometry that shares most of the components from the conventional CRM-HL configuration based on the design of Lacy and Sclafani, ${ }^{28}$ except for the fowler flap that is replaced by a simple hinged flap geometry. This hinged flap geometry is also known as the simplified CRM-HL or CRM-SHL configuration. Multiple rows of fluidic actuators are embedded in the flap to control flow separation on the highly deflected flap $\left(50^{\circ}\right.$ flap deflection) and to recover the lift characteristics comparable to the conventional CRM-HL configuration. All the major components of the current AFCenabled CRM-SHL configuration, such as, slats, main wing, nacelle-pylon and flaps are shown in Fig. 2 (a). Because of the small size of actuators that are embedded inside the flaps, one can not see such components in a global view presented in Fig. 2 (a). However, the footprint of the actuator exits is visible on the top surface of flaps in the zoomed view presented in Fig. 2 (b). Three rows of actuators on the inboard flap, and two rows of actuators on the outboard flap are made visible in Fig. 3 by rendering the flaps as transparent surfaces in order to show the internal arrangement of the fluidic actuators. Compressed air is supplied through 10 feed tubes (four for inboard and six for outboard flap) to settling chambers that connect to the actuators. The baseline configuration contains a total of 120 fluidic actuators arranged in the manner shown in Fig. 3, and spaced 1.5 inches apart in the spanwise direction.

The semispan for the wing is 115.675 inches, and the mean aerodynamic chord in stowed (cruise) configuration is 27.58 inches at a span station of 46.875 inches. The planform area $\left(A_{r e f}\right)$ used for normalizing force coefficients is 2973.6 square inches. The computations are performed at a freestream Mach number of 0.2 , and Reynolds number of 3.27 million based on mean aerodynamic chord (mac) of the model, corresponding to the expected $14 \times 22$ windtunnel conditions. The fuselage (247.05 inches long) is attached to the wind-tunnel floor via a 3.5-inch-thick standoff plate (see Fig. 2 (a)), which can be rotated to change the angle of attack of the model relative to the incoming stream. Computations are performed for both the in-tunnel and the free-air modes to assess the effect of tunnel blockage on the aerodynamic characteristics. A simplified approach is used for modeling the wind tunnel for in-tunnel simulations, where the CRM-SHL configuration is enclosed inside the rectangular test section of the wind tunnel. Slip boundary conditions are imposed on the tunnel walls and the floor up to the standoff plate, and velocity is imposed on the inflow boundary. No-slip boundary conditions are applied on the standoff plate and all of the exposed solid surfaces of the configuration. Pressure is specified at the wind tunnel outlet. For free air simulations, the tunnel walls are replaced with a large hemispherical domain of radius 50 times the fuselage length. Freestream pressure and velocity are imposed at the outer boundary of this hemispherical domain.

To simulate the flow in the actuators, total pressure and temperature inflow boundary conditions are imposed at the faces of inlet feed tubes and the complete flow field developing inside the actuators is computed. Due to the bistable nature of flow inside the fluidic actuators, unsteady oscillating jets (microjets) emanate from the actuator exit nozzles. The flow exiting the actuator nozzles energizes and interacts with the external flow over the flap surface, and reduces the reverse flow regions, thus resulting in increased lift. 


\section{Simulation Method}

Numerical simulations presented in this paper were performed using the commercial CFD software PowerFLOW ${ }^{\circledR}$, which is a compressible flow solver based originally on the three-dimensional 19 state (D3Q19) Lattice Boltzmann Method (LBM). The PowerFLOW ${ }^{\circledR}$ code represents LBM-based CFD technology developed over the last 30 years, ${ }^{30-34}$ and has been extensively validated for a wide variety of applications ranging from academic direct numerical simulations (DNS) cases to industrial flow problems in the fields of aerodynamics ${ }^{35}$ and aeroacoustics. ${ }^{36}$ In contrast to methods based on the Navier-Stokes (N-S) equations, LBM uses a simpler and more general physics formulation at the microscopic level. ${ }^{30}$ The LBM equations recover the macroscopic hydrodynamics of the Navier-Stokes equations ${ }^{37,38}$ through the Chapman-Enskog expansion.

The PowerFLOW ${ }^{\circledR}$ code can be used to solve the Lattice-Boltzmann equation in a DNS mode, ${ }^{39}$ where all of the turbulent scales are spatially and temporally resolved. However, for most engineering problems at high Reynolds numbers, the simulations are usually conducted in conjunction with a hybrid turbulence modeling approach where the smaller scales are modeled and larger, energy-containing scales are directly resolved. For the current work, the LatticeBoltzmann Very Large Eddy Simulation (LB-VLES) approach described in Refs. 32, 33 and 40 is used. All of the results presented here were obtained using the fully compressible version of the PowerFLOW ${ }^{\circledR}$ code,${ }^{41-43}$ which can be run in low speed, high subsonic or transonic mode. No-actuation, and lower pressure ratio cases are run using the high subsonic mode of the PowerFLOW ${ }^{\circledR}$ code. The higher pressure ratio cases $(\mathrm{P}>2.0)$ are run using the transonic mode, because the local Mach number inside the actuators can exceed sonic speed for such cases. For example, local Mach number in the vicinity of throat region reaches a maximum value of approximately 1.2 for the $\mathrm{P}=2.5$ case. The maximum Mach number observed on the suction surface of the slat is approximately 0.6 for these simulations.

The standard Lattice-Boltzmann boundary condition for no-slip or the specular reflection for free-slip condition is generalized through a volumetric formulation ${ }^{30,31}$ near the wall for arbitrarily oriented surface elements (surfels) within the Cartesian volume elements (voxels). This formulation of the boundary condition on a curved surface cutting the Cartesian grid is automatically mass, momentum, and energy conserving, and is compatible with the general secondorder spatial accuracy of the underlying LBM numerical scheme. To reduce the resolution requirement near solid surfaces for high Reynolds number flows, a hybrid wall function is used to model the near-wall region of the boundary layer. $^{35,44}$

The Lattice-Boltzmann equation is solved on embedded Cartesian meshes, which are generated automatically within the flow solver for the configuration under consideration. Variable resolution (VR) regions can be defined to allow for local mesh refinement of the grid by successive factors of two in each direction. ${ }^{30}$ The PowerFLOW ${ }^{\circledR}$ code scales well on modern computer clusters consisting of thousands of processors, making it suitable for large scale applications.

The PowerFLOW ${ }^{\circledR}$ code uses explicit time marching to solve the governing equations in a time consistent manner. The time step used for advancing the solutions is based on stability considerations. The solution on a given VR level is updated twice as often when compared to the number of solution updates on the next coarser VR level. Thus, the solution on the finest grid is updated most frequently, whereas the solution on the coarsest grid is updated least often to advance the solution in the whole domain to the same physical time. A comparable number of voxels (cells) on coarser grid levels are therefore less expensive from the computational point of view.

\section{Results}

The computations of the three-dimensional (3-D) flow field for the AFC-enabled CRM-SHL configuration have been performed using the fully compressible version of the PowerFLOW ${ }^{\circledR}$ code. The baseline configuration with the slats and flaps set for the landing configuration was simulated at $8^{\circ}$ angle of attack. As seen in Fig. 3, this configuration consists of multiple rows of fluidic actuators on the flaps (three rows on the inboard flap and two rows on the outboard flap) for flow control. The computational setup has the flexibility to turn on or off any of the individual actuators, thus allowing us to examine the effect of individual actuators or rows of actuators on the aerodynamics characteristics and lift augmentation. This is easily accomplished by including solid blockage parts at the actuator inlets that can be enabled or disabled during the discretization and setup stage.

\section{IV.A. In-tunnel Simulations}

The first set of simulations were performed for the CRM-SHL configuration enclosed inside the $14 \times 22$ wind tunnel, where the fuselage is attached to the wind-tunnel floor as shown in Fig. 2 (a). As mentioned in an earlier section, the computations are performed on embedded Cartesian meshes, which are generated within the flow solver. For the current configuration, a total of 13 variable resolution (VR) regions were used, where finer resolution was specified for high 
gradient regions, such as the suction surface of slats, main wing and flaps. The variation in grid density for lifting surfaces is illustrated in Fig. 4 with a planar cut of the grid at the span station of $y=27.75$ inches, where every other line is shown for improved clarity. Based on previous experience with the PowerFLOW ${ }^{\circledR}$ code, the normal spacing was chosen to produce an average value of 120 for $y^{+}$on lifting surfaces.

The finest VR was used for discretizing the internal domain in the vicinity of the actuator throat nozzles. A minimum of $8 \times 16$ voxels were used at the throat for these simulations based on the experience gained during the grid sensitivity study conducted for a single actuator. ${ }^{45}$ The voxels in the finest VR region have an edge length of 0.00567 inches. The resulting grid consisted of approximately 456 million voxels (cells). VR regions were also created to capture the vortical regions emanating from the slat edges, fuselage/wing and nacelle/pylong junctures, and the wing tip.

Since the flow field is inherently unsteady, the computations are run long enough in time for the flow to achieve a quasisteady state, as determined by the variation of the integrated forces (e.g., lift) in time for a given case. Computations are typically run for a physical time of 0.5-0.6 seconds, which corresponds to the time required for traveling a distance of approximately 50 chord lengths. This allows us to extract time-averaged solutions for surface pressure and streamlines, and to make quantitative comparisons among different configurations and flow conditions. A parametric study was conducted where the pressure ratio at the inlet feed tube was varied from 1.25 to 3.0. Examination of the flow inside the actuator nozzles indicated the presence of sonic flow for pressure ratios of 2.5 and higher. Simulations were also performed with the actuation being turned off completely (No AFC), to serve as a baseline for assessing the effectiveness of AFC for lift augmentation.

Time-averaged surface pressure $\left(\mathrm{C}_{p}\right)$ distributions were extracted at spanwise cuts shown in Fig. 5, which correspond to the locations where experimental data will be acquired in the $14 \times 22$ wind tunnel. The effect of varying the pressure ratio $(\mathrm{P})$ at the inlet feed tubes on sectional $\mathrm{C}_{p}$ distributions are compared in Fig. 6 at several spanwise locations, including the midsection of the inboard flap ( $\mathrm{y}=27.75$ inch), top of nacelle ( $\mathrm{y}=38.05$ inch), midsection of the outboard flap ( $\mathrm{y}=63.8 \mathrm{inch})$, and an outboard section of wing $(\mathrm{y}=94.7 \mathrm{inch})$ that does not contain any actuators. The results obtained for the case without any actuation (No AFC) are also shown in these figures. A close examination of surface pressure distributions indicates a systematic increase in suction pressure levels on the upper surface of the main wing and flap, as the inlet feed tube pressure is increased. In addition, at least a partial recovery of the trailing edge pressure is observed for higher pressure ratios. Since AFC has practically no effect on lower surface pressure distributions, the overall effect of AFC is an increase in integrated lift mainly due to the increase in upper surface suction pressure levels. Increasing the inlet pressure ratio beyond 2.0 has a very small effect on pressure distributions, especially on the outboard flap. Even at the $y=94.7$ inch location, which does not contain any actuators, the suction pressure levels are slightly higher at the leading edge for the actuated cases, most probably due to overall increase in the circulation level in the presence of actuation.

The variation of lift coefficient with pressure ratio is shown in Fig. 7, where a pressure ratio of 1 was assigned to the "No AFC" case for convenience. The total mass flow (mdot) entering all of the actuators (inboard and outboard flaps, or IB/OB) is also shown in this figure. It is clear from Fig. 7 that AFC results in a significant increase in lift coefficient, at least up to a pressure ratio of 1.75 . However, the lift coefficient starts tapering off between a pressure ratio of 1.75 and 2.0. In fact, we notice a slight drop in the lift coefficient for pressure ratios higher than 2.0. Similar trends in lift coefficient and mass flow were observed when we used AFC only on the inboard flap (IB), as seen in Fig. 7. This tapering of lift was initially believed to be caused by the inability of forcing higher mass flow through feed tubes, once the actuators are choked at higher pressure ratios. However, that is clearly not the case since the mass flow indicates a near linear growth with the pressure ratio. A possible cause for tapering of the lift is discussed later in the next section.

From a system integration point of view, it is also important to examine the effect of mass flow on the lift coefficient, since the amount of compressed air available on a flight vehicle for AFC usage is in limited supply. Therefore, we replotted the lift coefficient as a function of mass flow in Fig. 8 for these cases. The pressure ratios are also indicated next to the data points for clarity. Once again, the lift increases almost linearly for lower mass flow rates (and lower pressure ratios), and then tapers off and shows slight drop off beyond the mass flow that corresponds to the pressure ratio of 2.0. This is true whether actuation is used for both inboard and outboard (IB/OB) flaps, or only on the inboard (IB) flap. In addition, these results indicate that using AFC only on the inboard flap (IB) is more efficient for lift augmentation at lower pressure ratio in terms of mass flow required to achieve the same lift. For the higher pressure ratio cases, there is still an advantage regarding the maximum achievable lift when AFC is used on both the inboard and the outboard (IB/OB) flaps. Although not presented here, we also examined the effect of doubling the spacing between the actuators by blocking the airflow to alternate actuators on each row. The incremental lift/lb is higher for such simulations, but the lift coefficient for a given pressure ratio is much lower, making such an arrangement less desirable for maximizing the benefits of AFC for lift augmentation. 


\section{IV.B. Flow visualization}

The results presented so far are based on the surface pressure distributions, and one needs to look at off-surface flow characteristics to appreciate the effect of AFC on the resulting flow field. Contour plots of time-averaged velocity magnitude and streamline patterns for nonactuated (No AFC) case are compared with cases that were run with pressure ratios of 1.5, 2.0 and 3.0 in Figs. 9, 10, 11, for three spanwise cuts. These spanwise locations correspond to three of the locations for which surface $\mathrm{C}_{p}$ distributions were presented in Fig. 6.

The results for the midsection of the inboard flap ( $y=27.75$ inch) shown in Fig. 9 indicate that the extent of off-body reverse flow region is significantly reduced in the presence of AFC compared to the no actuation case. For a pressure ratio of 1.5, flow separation is still evident on the flap surface, whereas for a pressure ratio of 2.0, the flap appears to be fully attached. Interestingly enough, as the pressure ratio is increased further to 3.0, small pockets of reverse flow regions appear in the vicinity of the flap surface. At first, this result appeared to be very counterintuitive. However, a closer look at the streamline pattern indicates that if the actuators blow very high speed jets that are oriented at relatively large angles to the flap surface, the streamlines are displaced away from the flap resulting in such behavior. A possible solution is to decrease the inclination angle of the actuators by tilting the actuator nozzles further towards the flap surfaces in future configurations. However, there are practical limitations on such a strategy that are imposed by the size of chambers containing the actuators.

The streamline patterns shown in Fig. 10 for the section over the nacelle ( $y=38.05$ inch) also display reduction in the extent of reverse flow region in the presence of AFC. Once again, a pressure ratio of 2.0 produces a smaller reverse flow region compared to the 1.5 pressure ratio. Increasing pressure ratio to 3.0 does not seem to provide any additional benefit in this respect. Finally, examination of the results for the midsection of the outboard flap (y=63.8 inch) in Fig. 11 reveals that the current setup does not provide enough control authority to reduce the extent of off-body separation on the outboard flap.

As mentioned earlier, these simulations are run in time-accurate, unsteady mode and unsteady data is collected in critical regions for post analysis. For example, unsteady data at the middle of the actuator nozzle exits has been collected for these cases. Results based on spectral analysis of such data at an inboard ( $\mathrm{y}=23.55$ inch), and an outboard ( $\mathrm{y}=59.46$ inch) actuator exit are presented in Fig. 12, for pressure ratios of 2.5 and 3.0. The power spectral density (psd) plots indicate the presence of two dominant tones, which differ in frequency by a factor of 2 for a given pressure ratio. The frequency and the energy levels increase with increase in pressure ratio, a trend that has also been observed experimentally for such actuators. It is also noted that the fundamental frequency for the outboard actuator is approximately 1.5 times of the frequency for the inboard actuator. This is commensurate with experimental observations, and is due to the fact that the inboard actuators are larger in size $(0.06 \times 0.12 \mathrm{inch})$ compared to the outboard actuators $(0.04 \times 0.08 \mathrm{inch})$.

\section{IV.C. Free-air Simulations}

For the next set of calculations, the computational domain was created by expanding the outer boundaries starting from the tunnel walls, and forming a large hemispherical domain where far-field conditions can be imposed. The computational domain and associated grids used for the in-tunnel simulations form a subset of this expanded computational domain that has been created for the free-air simulations. All the test conditions and Reynolds numbers used here correspond to the in-tunnel cases. The primary purpose of these computations is to assess the effect of tunnel blockage on aerodynamic characteristics.

Computations were performed for pressure ratios up to 2.5 in the free-air mode. In addition, solutions were also obtained by turning off the actuation completely to assess the effectiveness of actuation on lift enhancement. The lift coefficients for in-tunnel and free-air modes are compared in Fig. 13, for pressure ratios varying from 1 (no-actuation) to 2.5. The highest value of lift coefficient is obtained for a pressure ratio of 2.0 for both sets of simulations. However, the actual value of lift obtained in free-air mode is smaller compared to the in-tunnel mode for the entire range of pressure ratios considered here due to tunnel blockage effect. The maximum lift coefficient predicted for the in-tunnel mode is about 0.11 higher compared to the free-air simulations.

Next we compare the increment in lift due to actuation for these two sets of simulations in Fig. 14. Here we compare $\Delta C_{L}=C_{L}-C_{L_{N o A F C}}$, as a function of mass flow used for actuation. Initially, the lift increases almost linearly with mass flow. However, the lift plateaus at a pressure ratio of 1.75 for both of these configurations, even though the mass flow increases continuously as the pressure ratio is increased. Although the lift increments are nearly identical for pressure ratios of 1.5 and lower, a slightly larger increment in lift is observed for the in-tunnel simulations at higher pressure ratios.

Additional insight about aerodynamic characteristics in general, and lift in particular is gained by examining the flow field based on these simulations. To that end, streamline patterns at an inboard ( $y=27.75$ inch), and an outboard ( $y=38.05$ 
inch) flap location are compared for these cases in Figs. 15 and 16 for a pressure rato of 2.0. The reverse flow region over the flaps are found to be much smaller for the in-tunnel simulations compared to the free-air simulations, which results in higher lift for the in-tunnel case.

\section{IV.D. Reconfiguartion of Inboard Actuators}

As a final set of free-air simulations, it was decided to evaluate the effect of reducing the number of inboard rows by eliminating the middle row of actuators on the inboard flap, which made it feasible to use slightly bigger actuators. The actuators on the outboard flap were unchanged during these free-air simulations. The integrated lift obtained for the new configuration (2 IB rows) is compared with the baseline configuration (3 IB rows) results in Fig. 17, for pressure ratios up to 2.5. As seen in this figure, the elimination of the middle row of actuators results in reduced lift for pressure ratios up to 2.0, the difference getting smaller as the pressure ratio is increased beyond 1.5. However, it should be noted that the corresponding mass flow requirement is also reduced when only 2 rows of actuators are used on the inboard flap. This is easier to see in Fig. 18, where the incremental lift $\left(\Delta C_{L}=C_{L}-C_{L_{N o A F C}}\right)$ is plotted as a function of mass flow. The mass flow required for a specified level of incremental lift is lower for the configuration that has 2 rows of actuators on the inboard flap, making such an arrangement more energy efficient. For example, the new configuration (2 IB rows) requires approximately $20 \%$ less mass flow compared to the baseline configuration ( $3 \mathrm{IB}$ rows) to achieve a comparable increment in lift at a pressure ratio of 2.0. It is believed that the small difference in lift (0.01) for these configurations in the absence of actuation (No AFC) is caused by the minor differences in these geometries, which produces a slight shift in the lift curve at lower pressure ratios.

It is instructive to examine the 3-D flow field over suction surface of the main wing and the flaps to assess the effect of actuation on reverse flow regions. Unfortunately, assessment of reverse flow extent for complex 3-D configurations is not straight forward, especially in the presence of vortices generated by wing/fuselage and nacelle/pylon junctures, and typical surface streamline patterns are found inadequate for this purpose. Instead, it was decided to compare 3-D streamline patterns along with total pressure $\left(C_{p t}\right)$ isosurfaces for these cases. It is well known that high total pressure losses are encountered in boundary layer and flow separation regions. A total pressure isosurface created with a value of $C_{p t}=0$ encompasses all regions of flow where total pressure deficit is present. Since flow separations cause higher total pressure losses, a value of -0.35 was chosen for the $C_{p t}$ isosurfaces in order to isolate these regions for visualization purposes. Such comparisons for the 2 IB row configuration based on free air simulations are presented in Figs. 19 - 23 for several actuation levels, starting from the nonactuated (No AFC) case. The streamlines and the $C_{p t}$ isosurface patterns shown in Fig. 19 indicate fully separated flow on both the inboard and the outboard flaps in the absence of actuation (No $\mathrm{AFC}$ ). These streamline patterns also indicate the existence of vortices generated by the wing/fuselage and nacelle/pylon junctures. A small reduction in the reverse flow region, and a slight weakening of corner vortex are observed on the inboard flap for the $\mathrm{P}=1.25$ case (Fig. 20). As the pressure ratio is increased further, reverse flow on the inboard flap keeps getting smaller in size. By the time the pressure ratio is increased to 1.75, the corner vortex disappears completely, and flow on the inboard flap appears to be fully attached except in the vicinity of the Yehudi break, as seen in Fig. 22 (a). The isosurface plot shown in Fig. 22 (b) is also indicative of a reduction in the reverse flow region on the inboard flap. However, the actuation appears to have only small effect on the outboard flap. When the pressure ratio is increased from 1.75 to 2.0 , it has only a minor effect on the flow field and the reverse flow region, which is probably the primary reason for plateauing of the lift curves at higher actuation (pressure) levels, as seen in Figs. 17 - 18.

\section{Concluding Remarks}

Computational results based on numerical simulations performed using a fully compressible Lattice-Boltzmann formulation in the PowerFLOW ${ }^{\circledR}$ CFD code, which has recently been validated for transonic and supersonic flow regimes, are presented here for a simplified high-lift CRM configuration in which the flap is embedded with multiple rows of fluidic actuators. Such actuators have been found to be very effective for flow control applications in the past. In the current approach, the entire flow field associated with this configuration, including the flow inside the actuators is simulated.

Results are presented here to examine the effect of varying the input pressure ratios to the fluidic actuators on surface pressure distributions and integrated forces. In general, the overall lift increases and reverse flow regions decrease with an increase in input pressure ratios (and hence the mass flow) used for actuation. However, the lift reaches a plateau at a pressure ratio of 2.0. Examination of the detailed flow field and streamline pattern indicates that the microjets blowing air at large angles to the flap surface tend to displace the flow away from solid surfaces and increase the extent of the reverse flow regions at higher pressure ratios $(\mathrm{P}>2.0)$.

Free-air simulations were also conducted by expanding the extent of the computational domain to quantify the effect of tunnel blockage on aerodynamic forces. In general, in-tunnel simulations indicate an increase of approximately 0.11 
in the maximum lift coefficient at higher pressure ratios compared to free-air simulations.

A preliminary study was conducted to assess the effect of eliminating the middle row of inboard actuators, which allowed the use of slightly larger actuators on the inboard flap. This new configuration was found to be more efficient in terms of achieving a comparable level of lift increment with less mass flow through the actuators.

The results presented here clearly indicate the usefulness of CFD to compare the performance of different types of actuator arrangements and thus help design more efficient AFC configurations prior to conducting wind tunnel tests. Future studies will focus on further optimization of the size and placement of actuators in order to maximize the lift enhancement with active flow control devices. This would include a comparison with cases where air is blowing through continuous slots and converging-diverging nozzles.

\section{Acknowledgments}

This work was supported by NASA Advanced Air Vehicles Program through the Advanced Air Transport Technology Project.

\section{References}

\footnotetext{
${ }^{1}$ Van Dam, C., "The Aerodynamic Design of Multi-Element High-Lift Systems for Transport Airplanes," Progress in Aerospace Sciences, Vol. 38, 2002, pp. 101-144.

${ }^{2}$ Greenblatt, D. and Wygnanski, I., "The Control of Flow Separation by Periodic Excitation," Progress in Aerospace Sciences, Vol. 36, 2000, pp. 487-545.

${ }^{3}$ Cattafesta III, L. and Sheplak, M., “Actuators for Active Flow Control," Annual Review of Fluid Mechanics, Vol. 43, 2010, pp. $247-272$.

${ }^{4}$ McClean, J., Crouch, J., Stoner, R., Sakrai, G., Feifel, W., and Rush, H., "Study of the Application of Separation Control by Unsteady Excitation to Civil Transport Aircraft," NASA CR-1999-209338, 1999.

${ }^{5}$ Hartwich, P., Camacho, P., El-Gohary, K., Gonzales, A., Lawson, E., and Shmilovich, A., "System-Level Trade Studies for Transonic Transports with Active Flow Control (AFC) Enhanced High-Lift Systems," AIAA Paper 2017-0321, January 2017.

${ }^{6}$ Hartwich, P., Shmilovich, A., Lacy, D., Dickey, E., Sclafani, A., Sundaram, P., and Yadlin, Y., "Refined AFC-Enabled High-Lift System Integration Study," NASA CR-2016-219170, 2016.

${ }^{7}$ Loftin, L., "Quest for Performance - The Evolution of Modern Aircraft," NASA SP-488, https://www.hq.nasa.gov/pao/History/SP-468/ch105.htm, 1985.

${ }^{8}$ DeSalvo, M., Whalen, E., and Glezer, A., "Enhancement of a High-Lift Airfoil using Low-Power Fluidic Actuators," AIAA Paper 2010-0863, June 2010.

${ }^{9}$ DeSalvo, M., Whalen, E., and Glezer, A., "High-Lift Enhancement using ActiveFlow Control," AIAA Paper 2011-3355, June 2011.

${ }^{10}$ Woszidlo, R. and Wygnanski, I., "Parameters Governing Separation Control with Sweeping Jet Actuators," AIAA Paper 2011-3172, June 2011.

${ }^{11}$ Vatsa, V., Koklu, M., Wygnanski, I., and Fares, E., "Numerical Simulation of Fluidic Actuators for Flow Control Applications," AIAA Paper 2012-3239, June 2011.

${ }^{12}$ Seele, R., Graff, E., Gharib, M., Taubert, L., Lin, J., and Wygnanski, I., "Improving Rudder Effectiveness with Sweeping Jet Actuators," AIAA Paper 2012-3244, June 2012.

${ }^{13}$ Seele, R., Graff, E., Lin, J., and Wygnanski, I., "Performance Enhancement of a Vertical Tail Model with Sweeping Jet Actuators," AIAA Paper 2013-0411, January 2013

${ }^{14}$ Graff, E., Seele, R., Lin, J., and Wygnanski, I., "Sweeping Jet Actuators - A New Design Tool for High Lift Generation,” NATO Workshop on Innovative Control Effectors for Military Vehicles (AVT-215), 2013, Stockholm, Sweden, May 20-22.

${ }^{15}$ Gregory, J. and Tomac, M., "A Review of Fluidic Oscillator Development and Application for Control,” AIAA Paper 2013-2474, June 2013.

${ }^{16}$ Melton, L. and Koklu, M., "Active Flow Control Using Sweeping Jet Actuators on a Semi-Span Wing Model," AIAA Paper 2016-1872, January 2016.

${ }^{17}$ Melton, L., Koklu, M., Andino, M., Y., Lin, J., and Edelman, L., “Sweeping Jet Optimization Studies,” AIAA Paper 2016-4233, June 2016.

${ }^{18}$ Jones, G., Milholen, W., Chan, D., and Goodliff, S., "A Sweeping Jet Application on a High Reynolds Number Semi-Span Supercritical Wing Configuration," AIAA Paper 2017-3044, June 2017.

${ }^{19}$ Shmilovich, A. and Yadin, Y., "Flow Control for the Systematic Buildup of High-Lift Systems," Journal of Aircraft, Vol. 45, No. 5, SeptemberOctober 2008, pp. 1680-1688.

${ }^{20}$ Shmilovich, A. and Yadin, Y., "Flow Control Techniques for Transport Aircraft," AIAA Journal, Vol. 49, No. 3, March 2011, pp. 489-502.

${ }^{21}$ Rumsey, C., Gatski, T., Sellers III, W., Vatsa, V., and Viken, S., "Summary of the 2004 Computational Fluid Dynamics Validation Workshop on Synthetic Jets," AIAA Journal, Vol. 44, No. 2, 2006, pp. 194-207.

${ }^{22}$ Collis, S., Joslin, R., Seifert, A., and Theofilis, V., "Issues in Active Flow Control: Theory, Control, Simulation and Experiment," Progress in Aerospace Sciences, Vol. 40, No. 4-5, 2004, pp. 237-289.

${ }^{23}$ Brès, G., Fares, E., Williams, D., and Colonius, T., "Numerical Simulations of the Transient Flow Response of a 3D, Low-Aspect-Ratio Wing to Pulsed Actuation," AIAA Paper 2011-3440, June 2011.

${ }^{24}$ Vatsa, V., Casalino, D., Lin, J., and Appelbaum, J., "Numerical Simulation of a High-Lift Configuration with Embedded Fluidic Actuators," AIAA Paper 2014-2142, June 2014.

${ }^{25}$ Vatsa, V., Duda, B., Fares, E., and Lin, J., "Numerical Simulation of a High-Lift Configuration Embedded with High Momentum Fluidic Actuators," AIAA Paper 2016-3932, June 2016.

${ }^{26}$ Vassberg, J., DeHaan, M., Rivers, S., and Wahls, R., "Development of a Common Research Model for Applied CFD Validation Studies,” AIAA Paper 2008-6919, August 2008.
} 
${ }^{27}$ NASA Common Research Model, URL: http://commonresearchmodel.larc.nasa.gov, last accessed, July 2017.

${ }^{28}$ Lacy, D. and Sclafani, A., "Development of the Common Research Model (HL-CRM): A Representative High Lift Configuration for Transonic Transports," AIAA Paper 2016-0308, January 2016.

${ }^{29}$ Lin, J., Melton, L., Viken, S., Andino, M., Koklu, M., Hannon, J., and Vatsa, V., "High-Lift Common Research Model for Wind Tunnel Testing: An Active Flow Control Perspective," AIAA Paper 2017-0319, January 2017.

${ }^{30}$ Chen, H., "Volumetric Formulation of the Lattice Boltzmann Method for Fluid Dynamics: Basic Concept," Physical Review A, Vol. 58, September 1998, pp. 3955-3963.

${ }^{31}$ Chen, H., Teixeira, C., and Molvig, K., "Realization of Fluid Boundary Conditions via Discrete Boltzmann Dynamics," Intl. J. Mod. Phys. C, Vol. 9, No. 8, 1998, pp. 1281-1292.

${ }^{32}$ Yakhot, V. and Orszag, S., "Renormalization Group Analysis of Turbulence. I. Basic Theory," J. Sci. Comput., Vol. 1, No. 2 , 1986, pp. 3-51.

${ }^{33}$ Chen, H., Kandasamy, S., Orszag, S., Shock, R., Succi, S., and Yakhot, V., "Extended Boltzmann Kinetic Equation for Turbulent Flows," Science, Vol. 301, No. 5633, 2003, pp. 633-636.

${ }^{34}$ Chen, S. and Doolen, G., "Lattice Boltzmann Method for Fluid Flows," Ann. Rev. Fluid Mech., Vol. 30, January 1998 , pp. $329-364$.

${ }^{35}$ Fares, E. and Nölting, S., "Unsteady Flow Simulation of a High-Lift Configuration using a Lattice Boltzmann Approach,” AIAA Paper 2011869 , January 2011.

${ }^{36}$ Khorrami, M., Fares, E., and Casalino, D., "Towards Full-Aircraft Airframe Noise Prediction: Lattice-Boltzmann Simulations," AIAA Paper 2014-2481, June 2014.

${ }^{37}$ Chen, H., Chen, S., and Matthaeus, W., "Recovery of the Navier-Stokes Equations Using a Lattice-gas Boltzmann Method," Physical Review A, Vol. 45, 1992, pp. 5339-5342.

${ }^{38}$ Qiana, Y. H., D’Humieŕes, D., and Lallemand, P., "Lattice BGK Models for Navier-Stokes Equations," Europhysics Letters, Vol. 17, 1992, pp. 479-484.

${ }^{39}$ Li, Y., Shock, R., and Chen, H., "Numerical Study of Flow Past an Impulsively Started Cylinder by Lattice Botzmann Method," J. Fluid Mech., Vol. 519, November 2004, pp. 273-300.

${ }^{40}$ Chen, H., Orszag, S., Staroselsky, I., and Succi, S., "Expanded Analogy between Boltzmann Kinetic Theory of Fluid and Turbulence," J. Fluid Mech., Vol. 519, November 2004, pp. 301-314.

${ }^{41}$ Shan, X., Yuvan, X.-F., and Chen, H., "Kinetic Theory Representation of Hydrodynamics: a Way Beyond the Navier-Stokes Equation," Physics. Rev. Lett., Vol. 80, 1998, pp. 65-88.

${ }^{42}$ Zhuo, C., Zhong, C., Li, K., Xiong, S., Chen, X., and Cao, J., "Application of Lattice Boltzmann Method to Simulation of Compressible Turbulent Flow," Commun. Comput. Physics, Vol. 8, 2010, pp. 1208-1223.

${ }^{43}$ Fares, E., Wessels, M., Li, Y., Gopalakrishnan, P., Zhang, R., Sun, C., Gopalaswamy, N., Roberts, P., Hoch, J., and Chen, H., "Validation of a Lattice Boltzmann Approach for Transonic and Supersonic Simulations," AIAA Paper 2014-0952, January 2014.

${ }^{44}$ Fares, E., "Unsteady Flow Simulation of the Ahmed Reference Body using a Lattice Boltzmann Approach," Comput. Fluids, Vol. 35, No. 8-9, 2006, pp. 940-950.

${ }^{45}$ Duda, B., Fares, E., Wessels, M., and Vatsa, V., "Unsteady Flow Simulation of a Sweepig Jet Actuator Using a Lattice-Boltzmann Method," AIAA Paper 2016-1818, January 2016. 


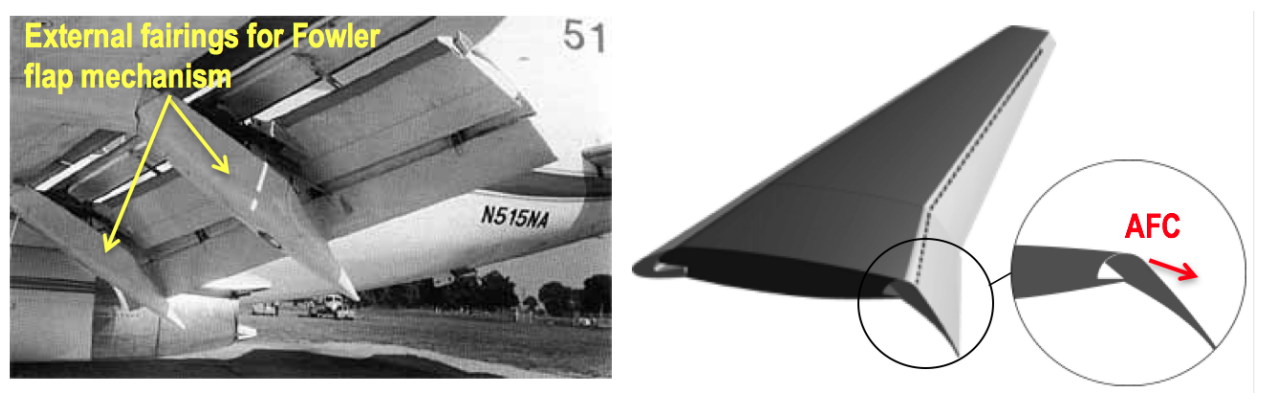

Figure 1. Schematic of Fowler flap and simple hinged flaps.

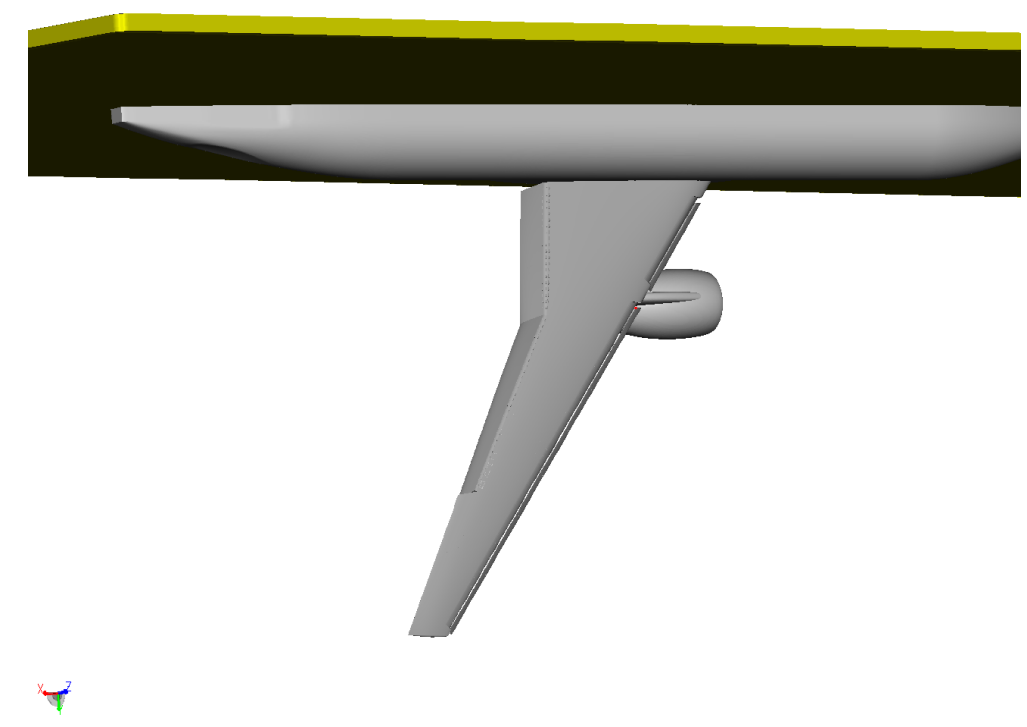

(a) global view

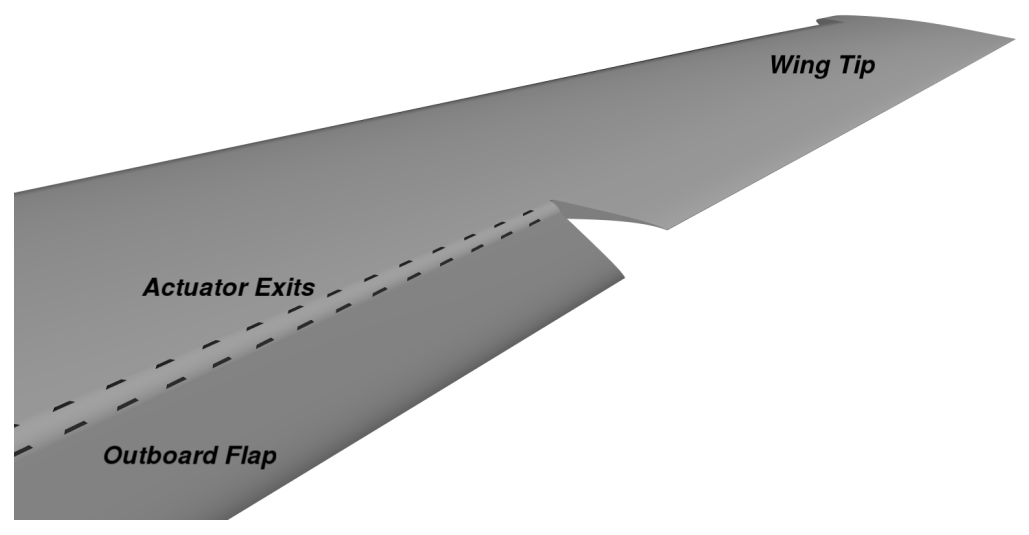

(b) zoomed view

Figure 2. Top view of simplified high-lift CRM configuration. 


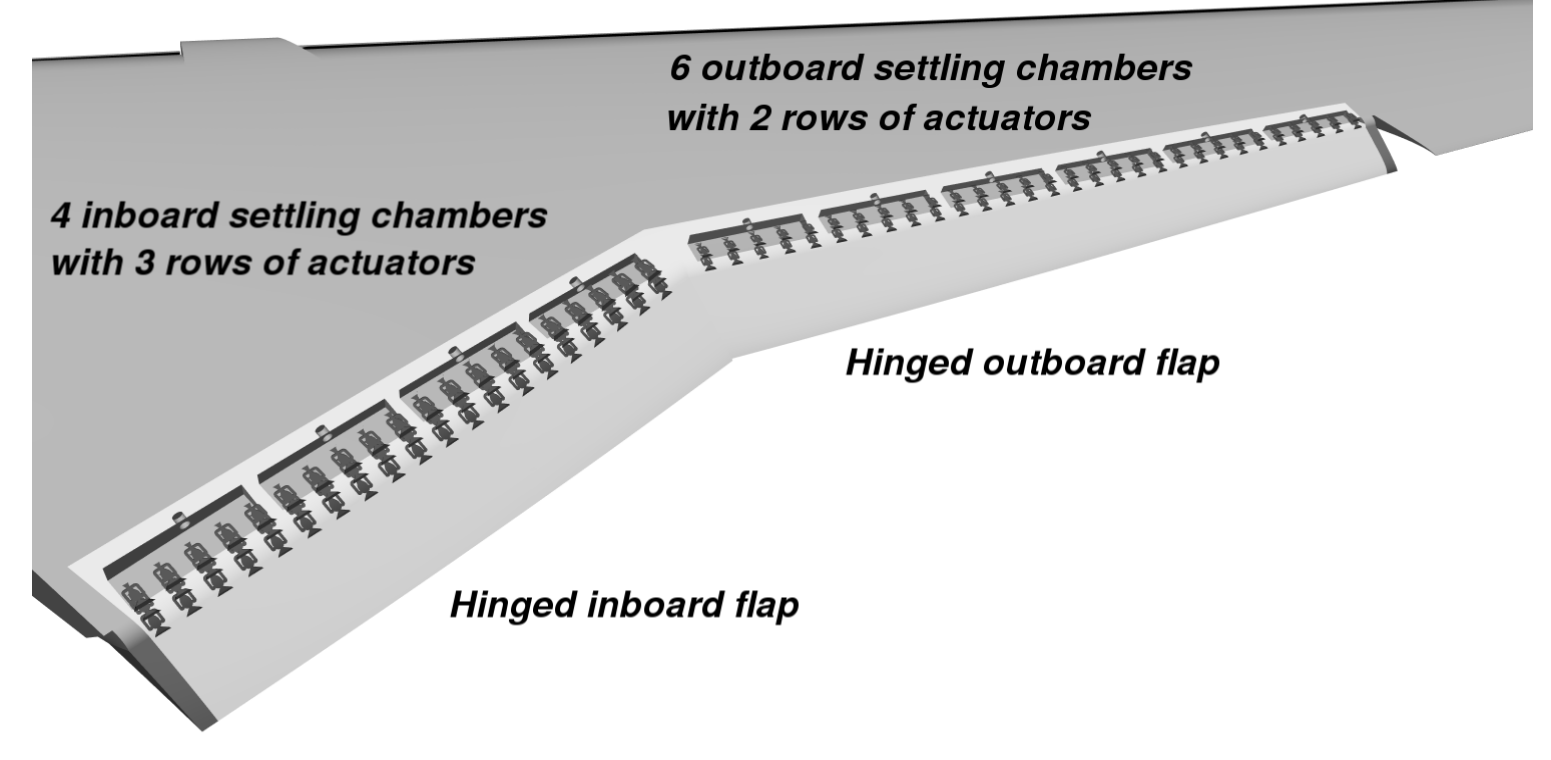

Figure 3. Detailed view of actuators for simplified high-lift CRM configuration.

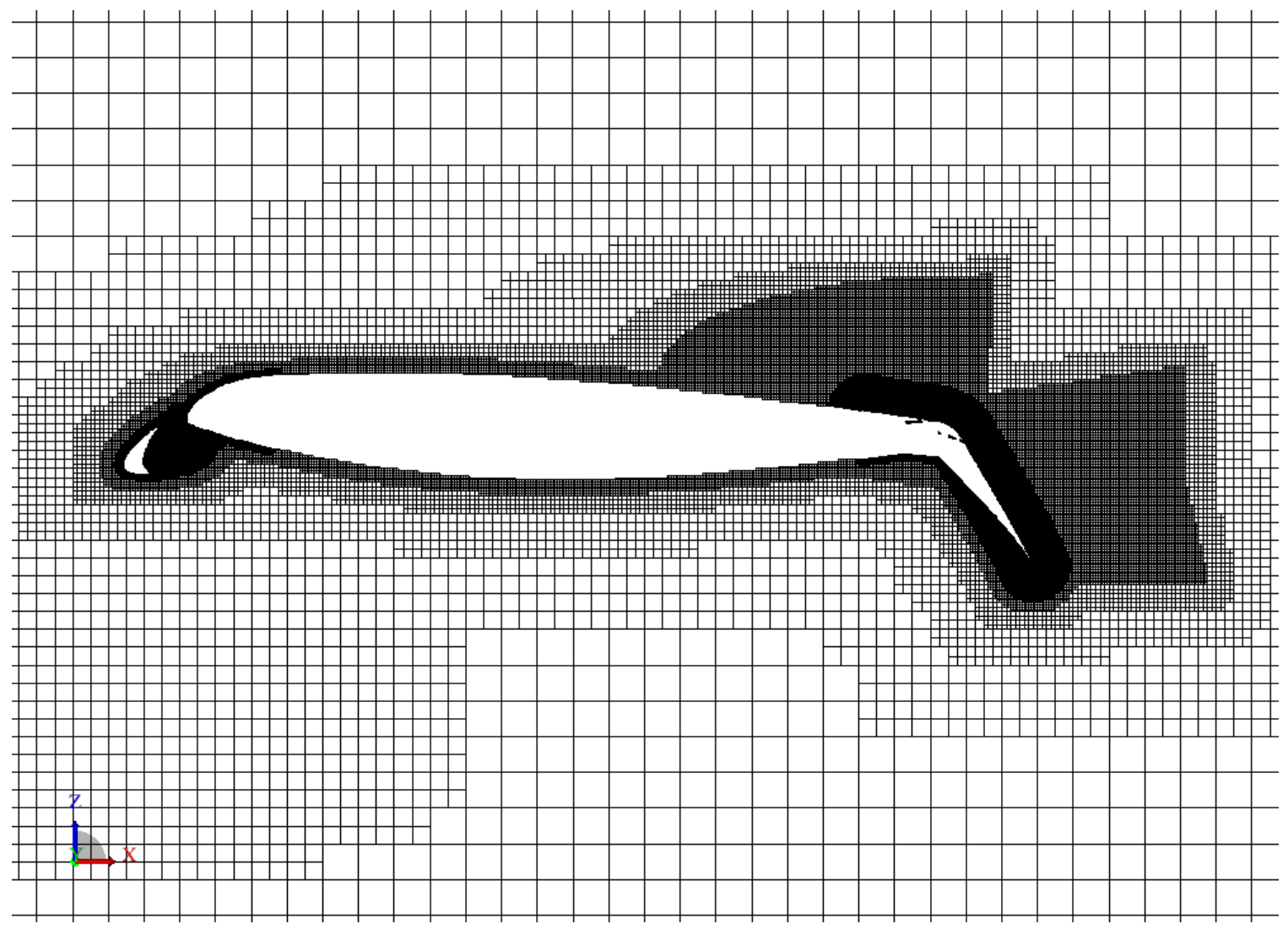

Figure 4. Grid density variation at a planar section, $y=27.75$ in. 


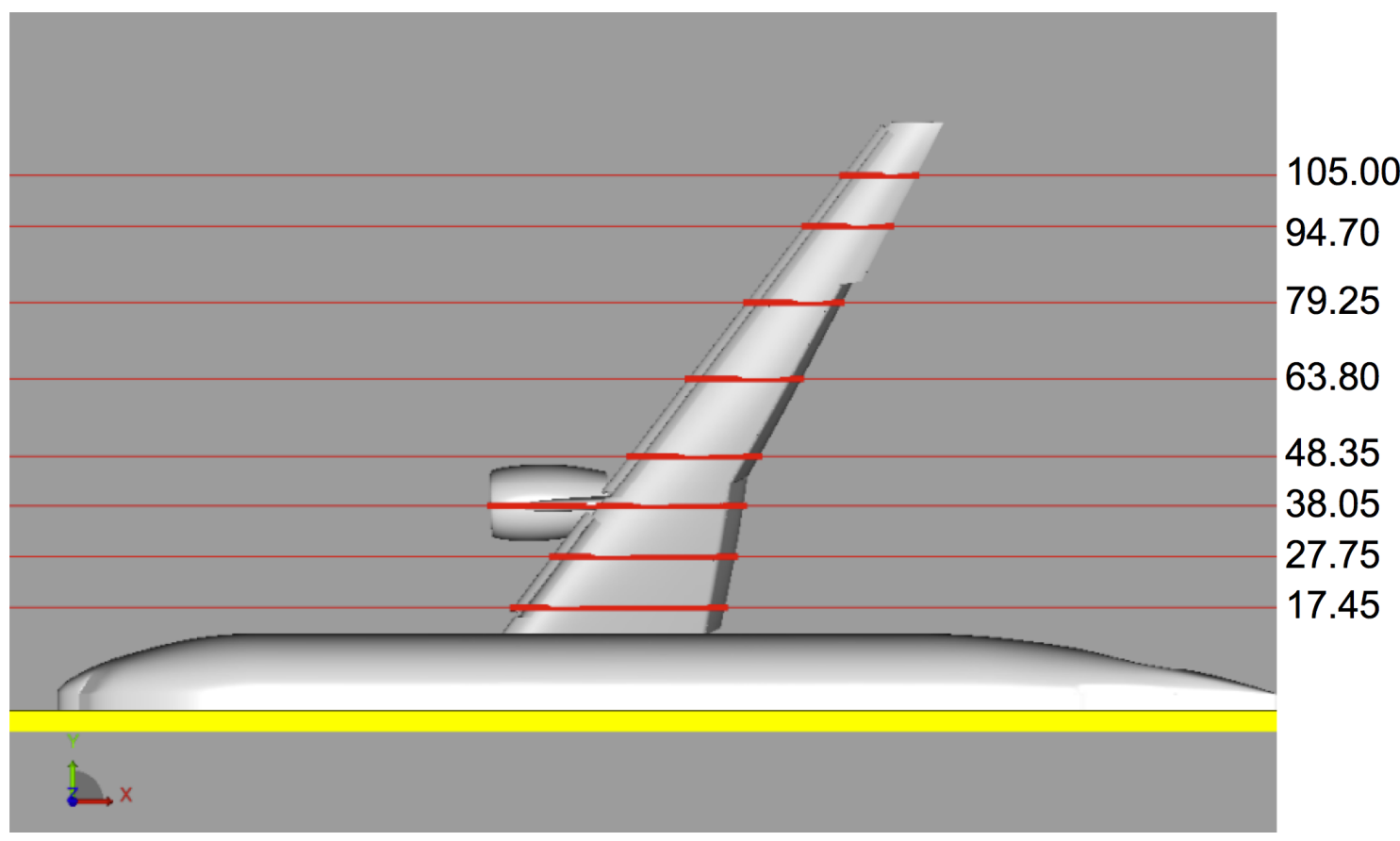

Figure 5. Schematic of spanwise pressure cut locations in inches. 


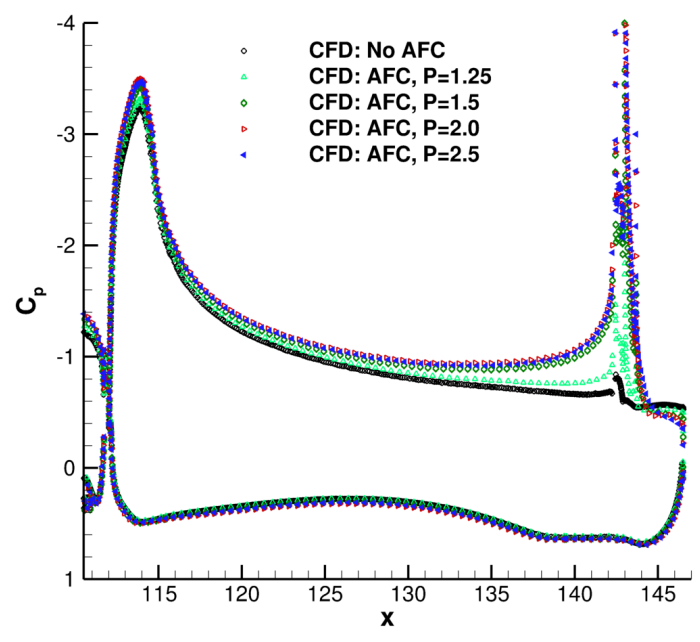

(a) 27.75 in.

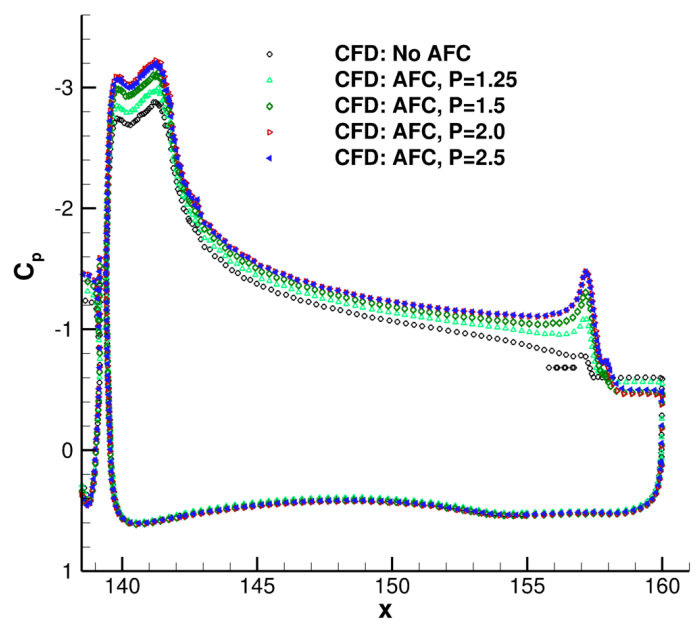

(c) $\mathbf{y}=63.80$ in.

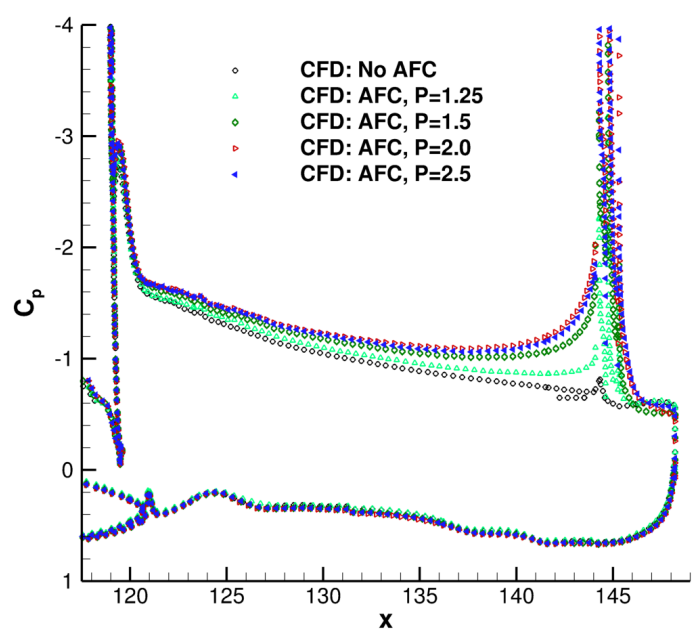

(b) $\mathbf{y}=38.05$ in.

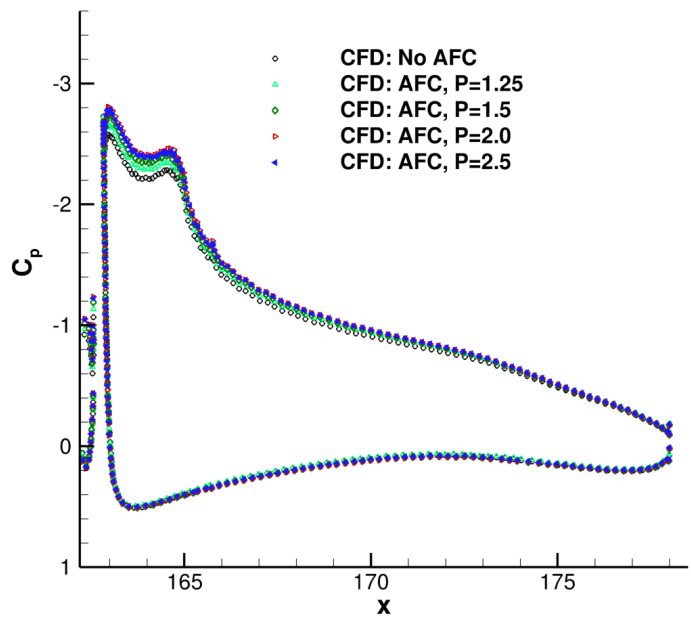

(d) $\mathbf{y}=94.70$ in.

Figure 6. Effect of feed tube pressure variation on sectional pressure coefficients. 


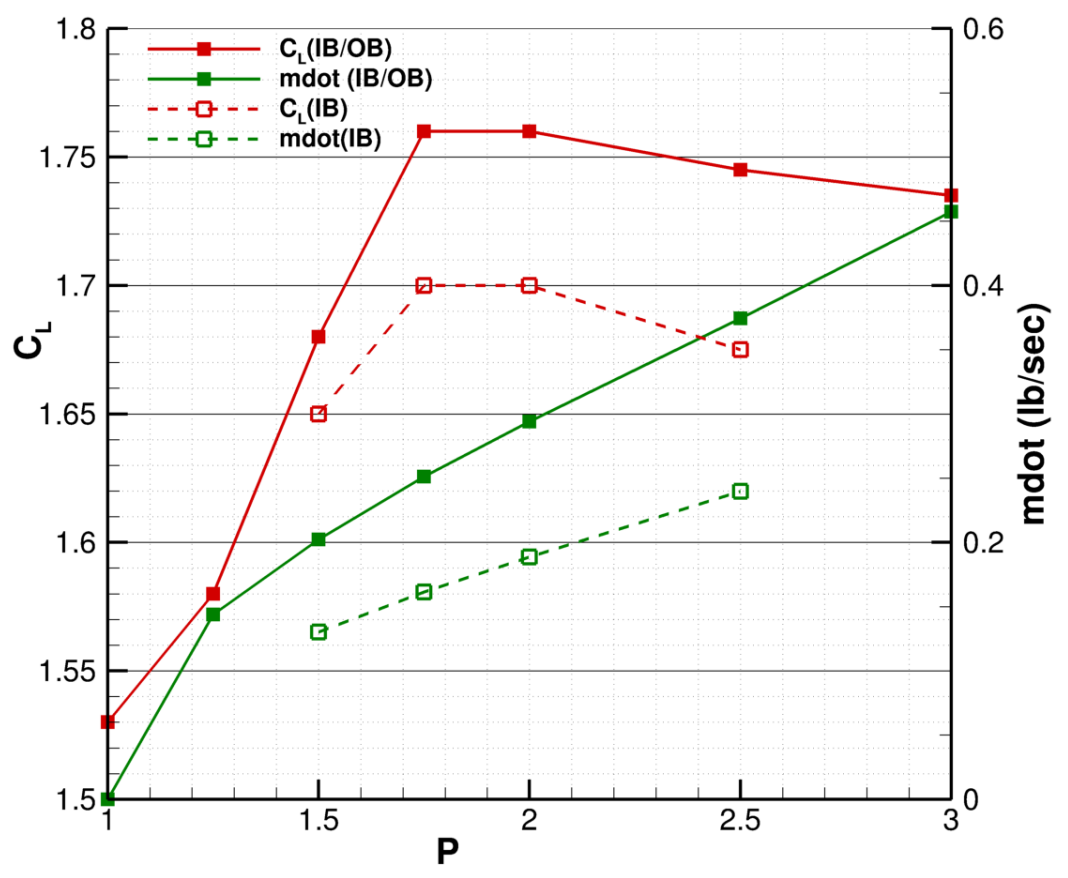

Figure 7. Effect of feed tube pressure variation on lift coefficient and mass flow.

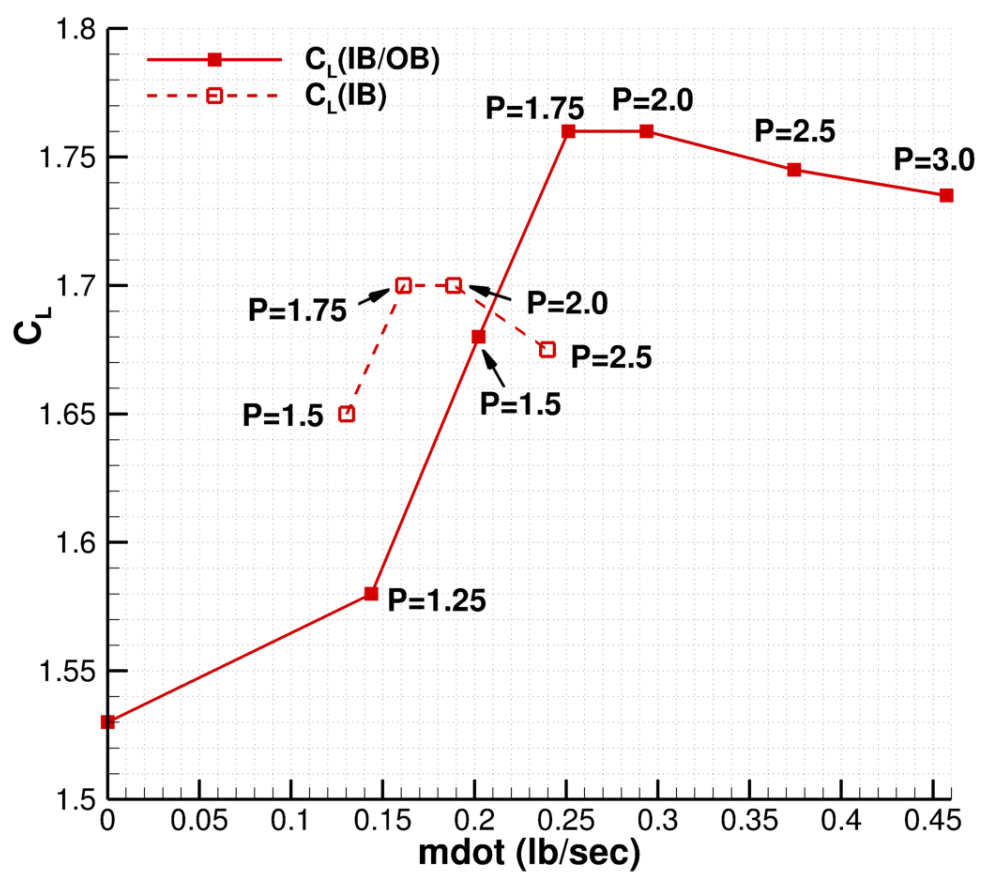

Figure 8. Effect of input mass flow variation on lift coefficient. 


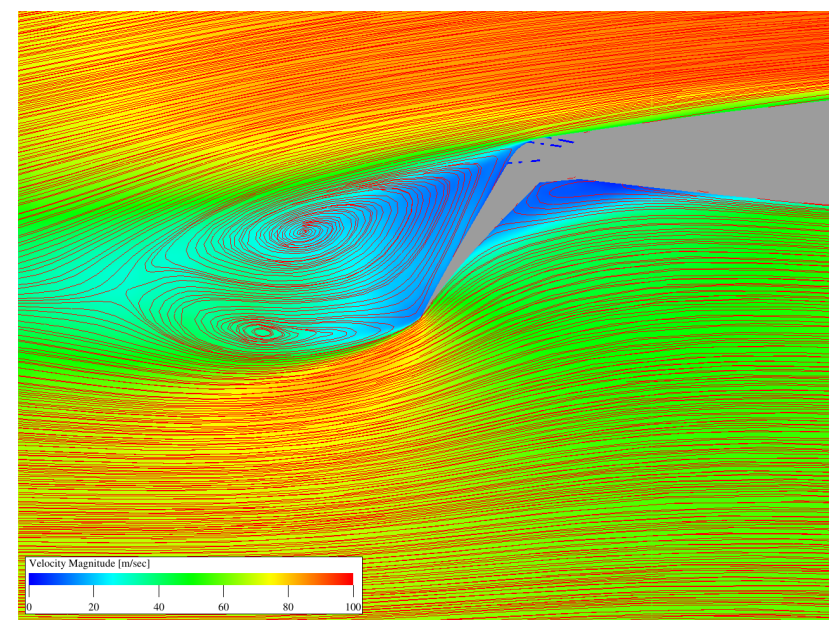

(a) No AFC

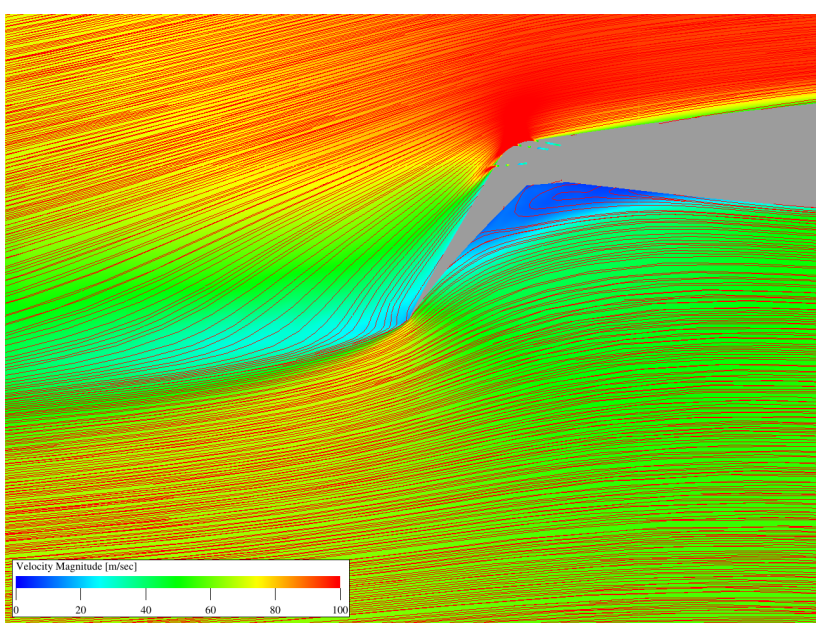

(c) AFC: P=2.0

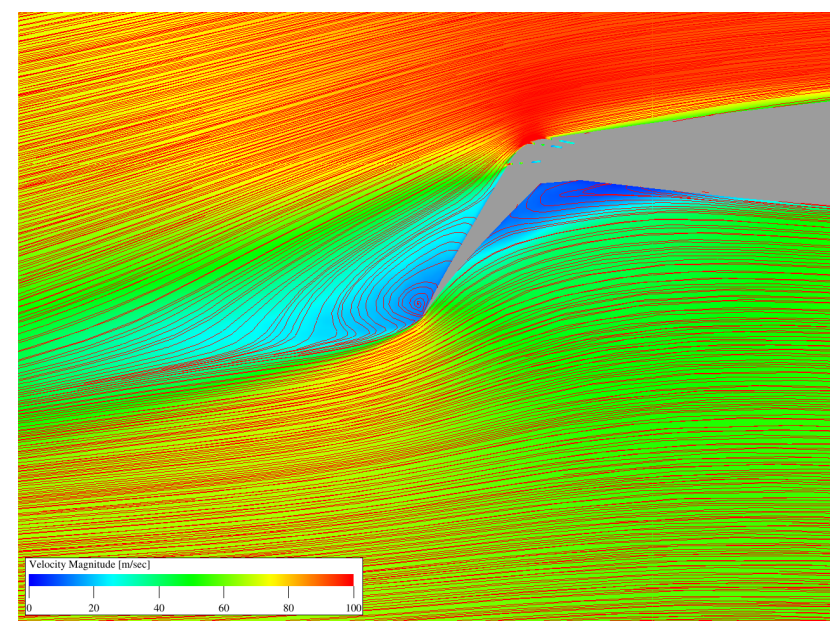

(b) AFC: $P=1.5$

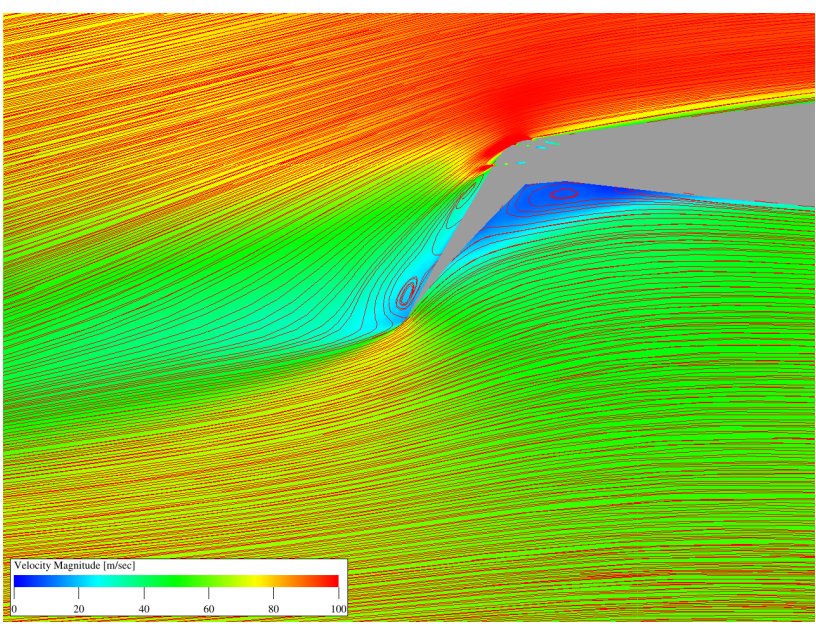

(d) AFC: $P=3.0$

Figure 9. Effect of feed tube pressure levels on simulated streamline patterns, $y=27.75$ in. 


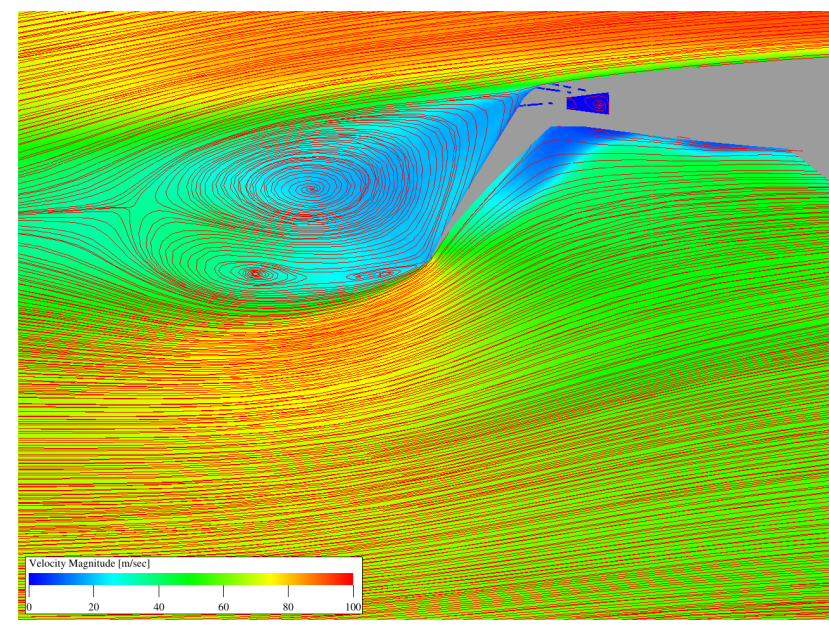

(a) No AFC

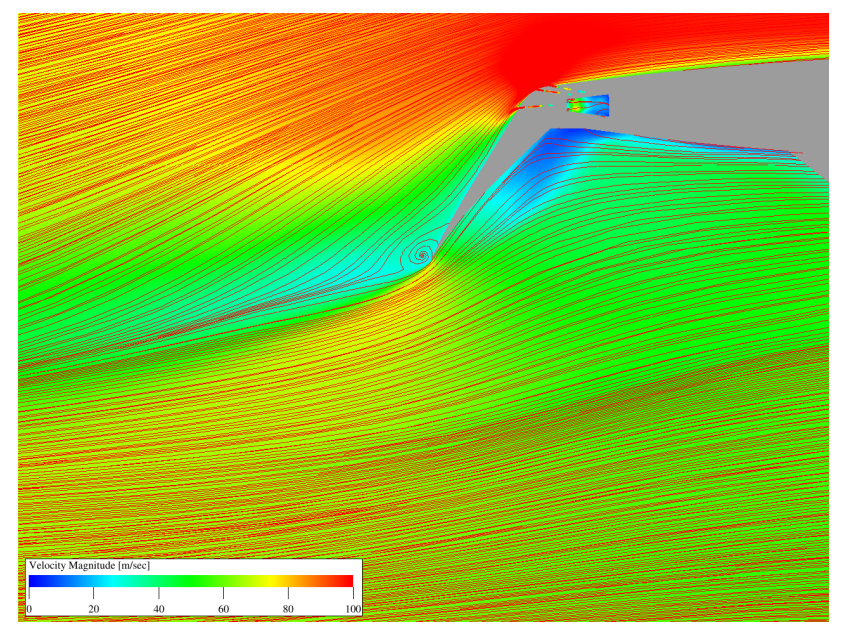

(c) AFC: P=2.0

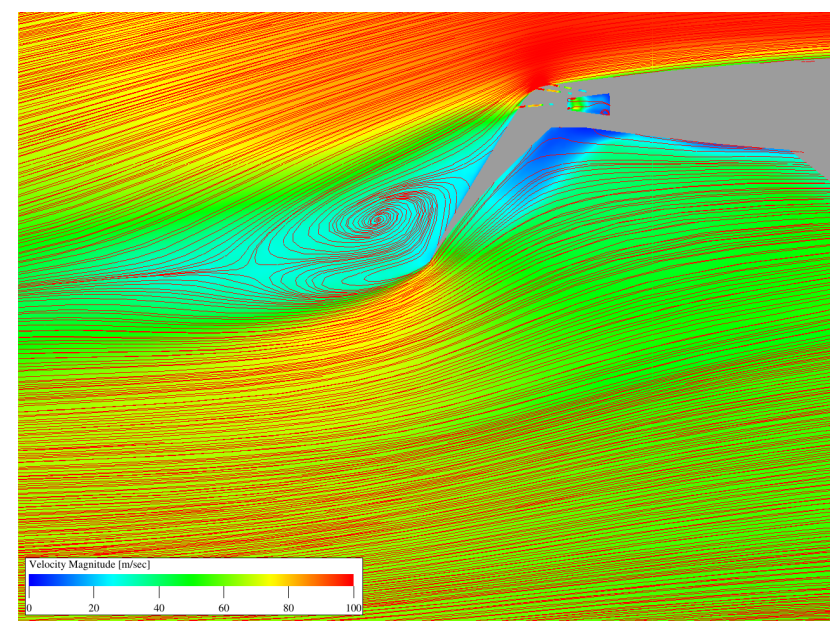

(b) AFC: $P=1.5$

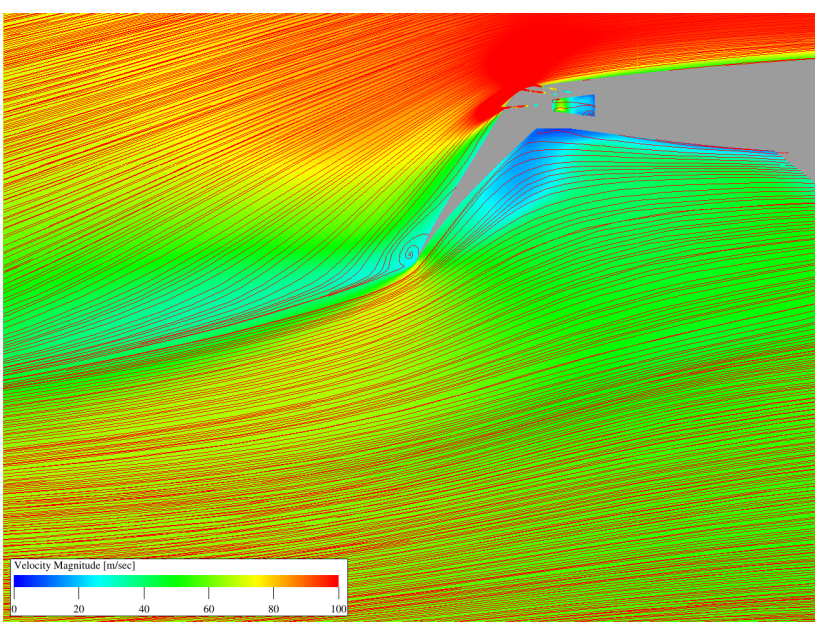

(d) AFC: $P=3.0$

Figure 10. Effect of feed tube pressure levels on simulated streamline patterns, $y=38.05$ in. 


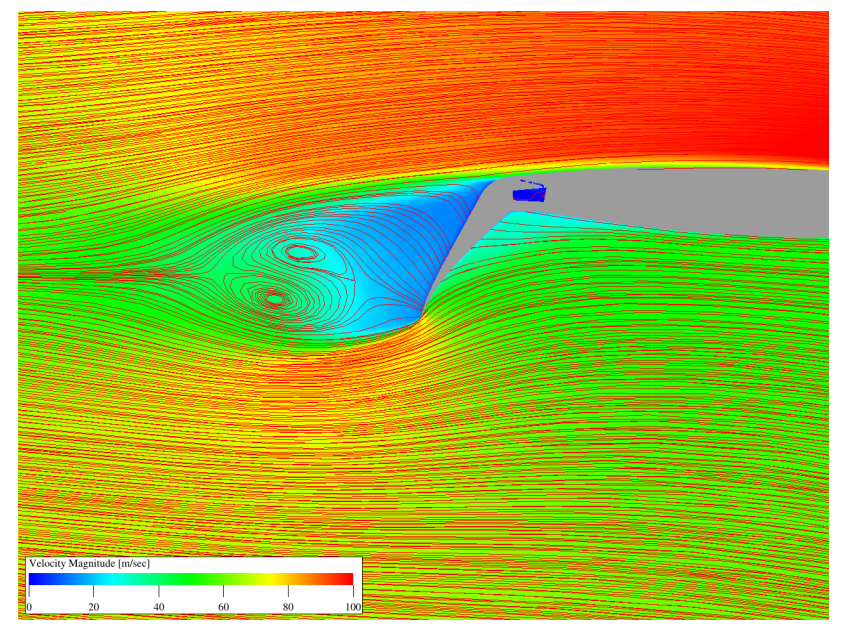

(a) No AFC

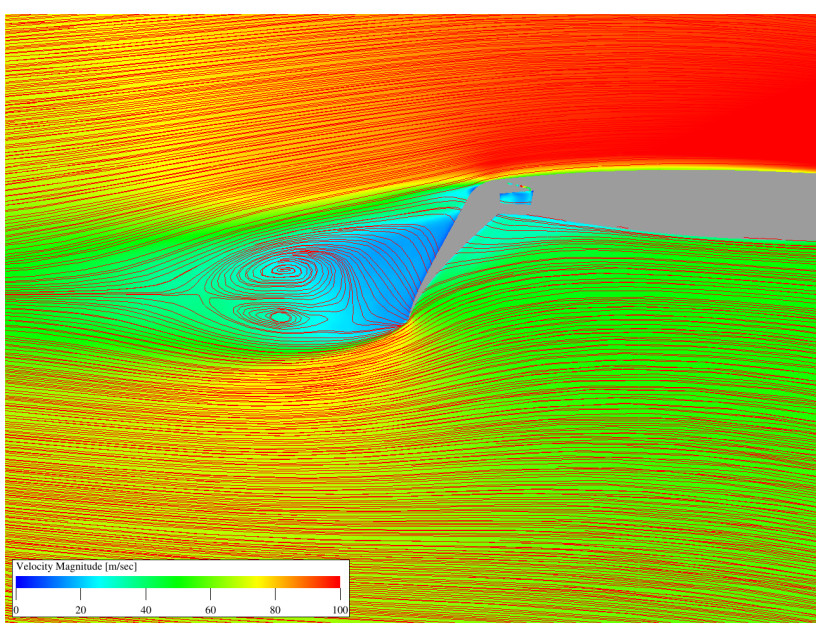

(c) AFC: P=2.0

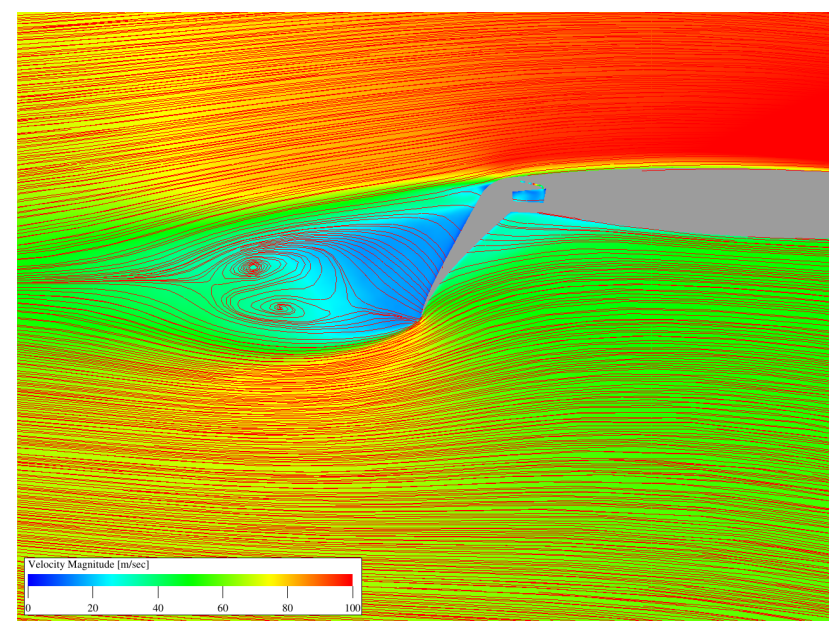

(b) AFC: $P=1.5$

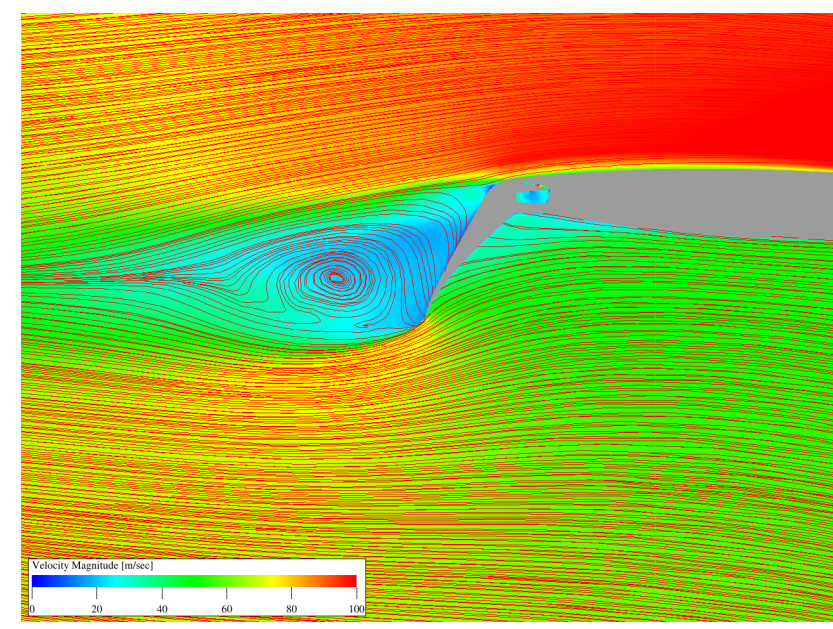

(d) AFC: $P=3.0$

Figure 11. Effect of feed tube pressure levels on simulated streamline patterns, $y=63.80 \mathrm{in}$. 


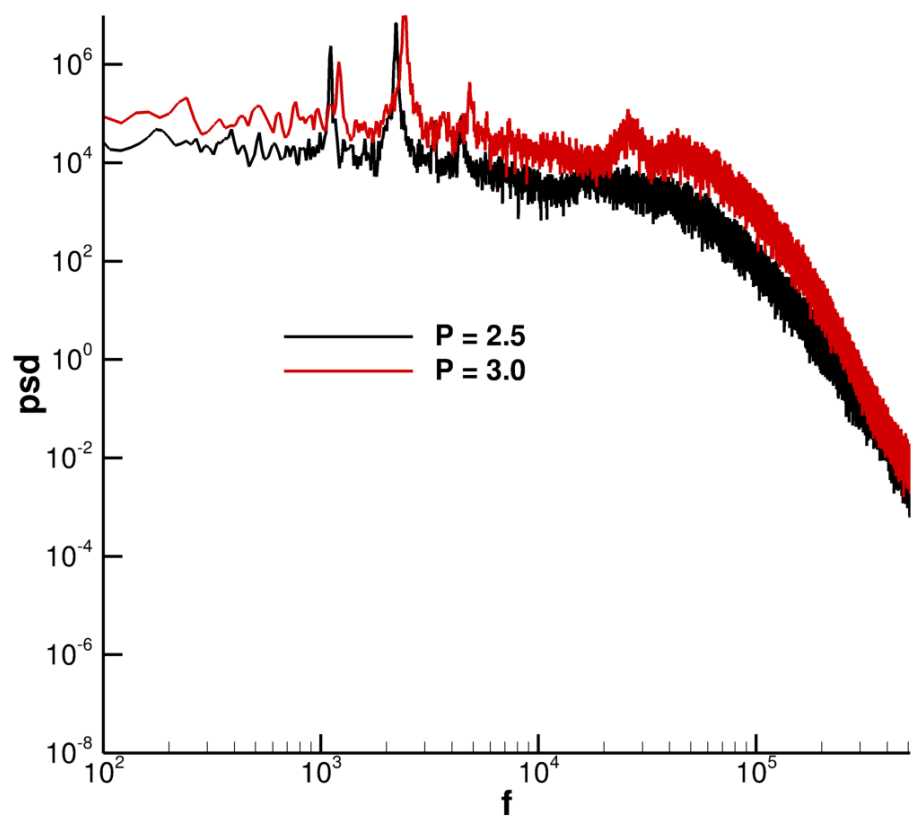

(a) Inboard actuator, $y=23.55$ in.

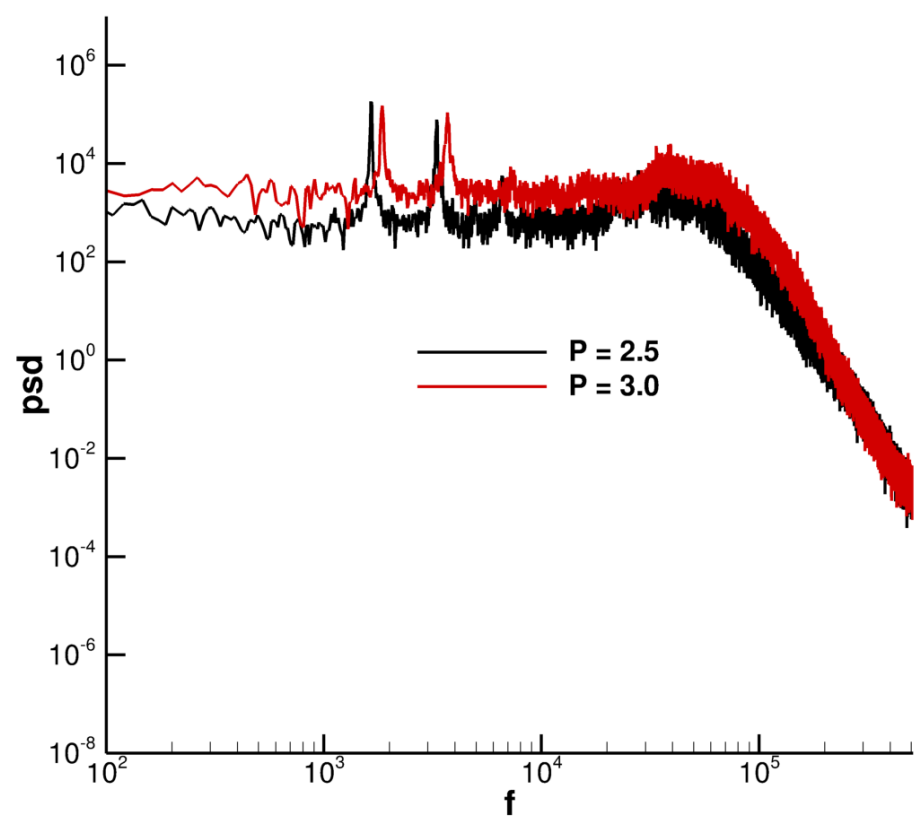

(b) Outboard actuator, 59.46 in.

Figure 12. Power spectral density distribution for actuator nozzle exit. 


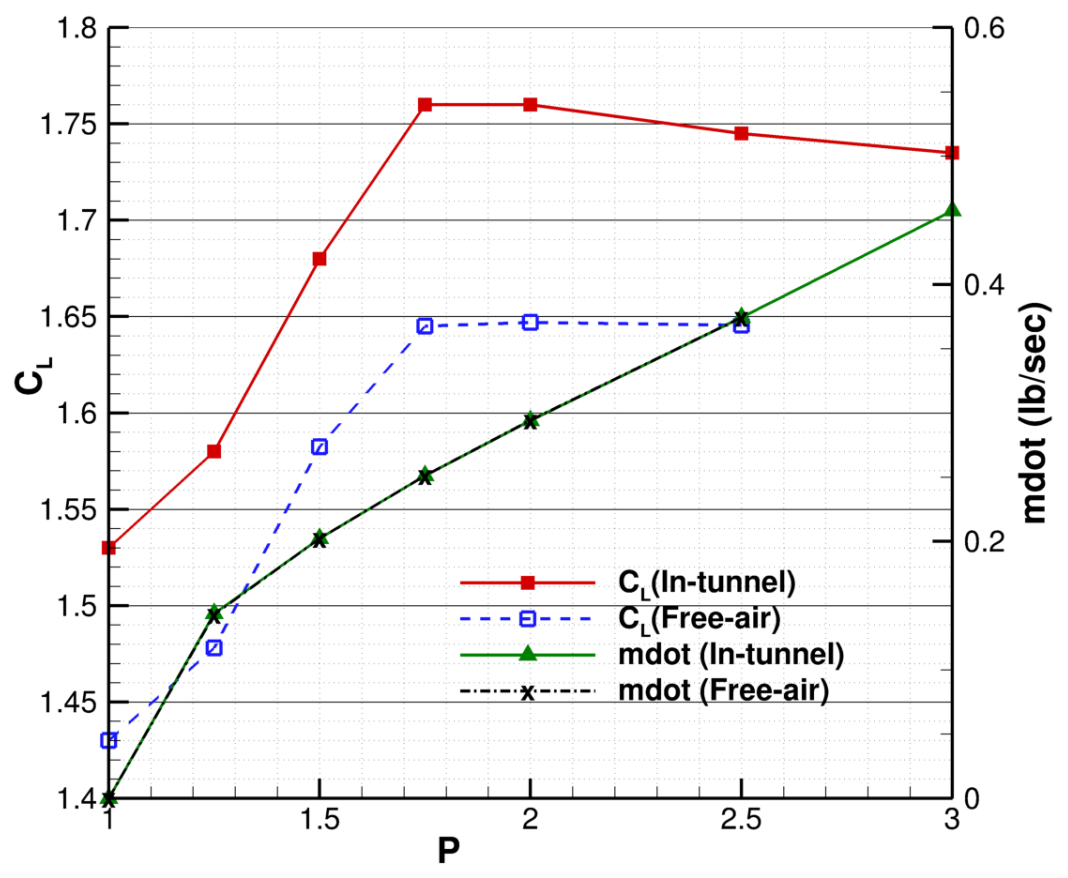

Figure 13. Effect of feed tube pressure variation on lift coefficient and mass flow.

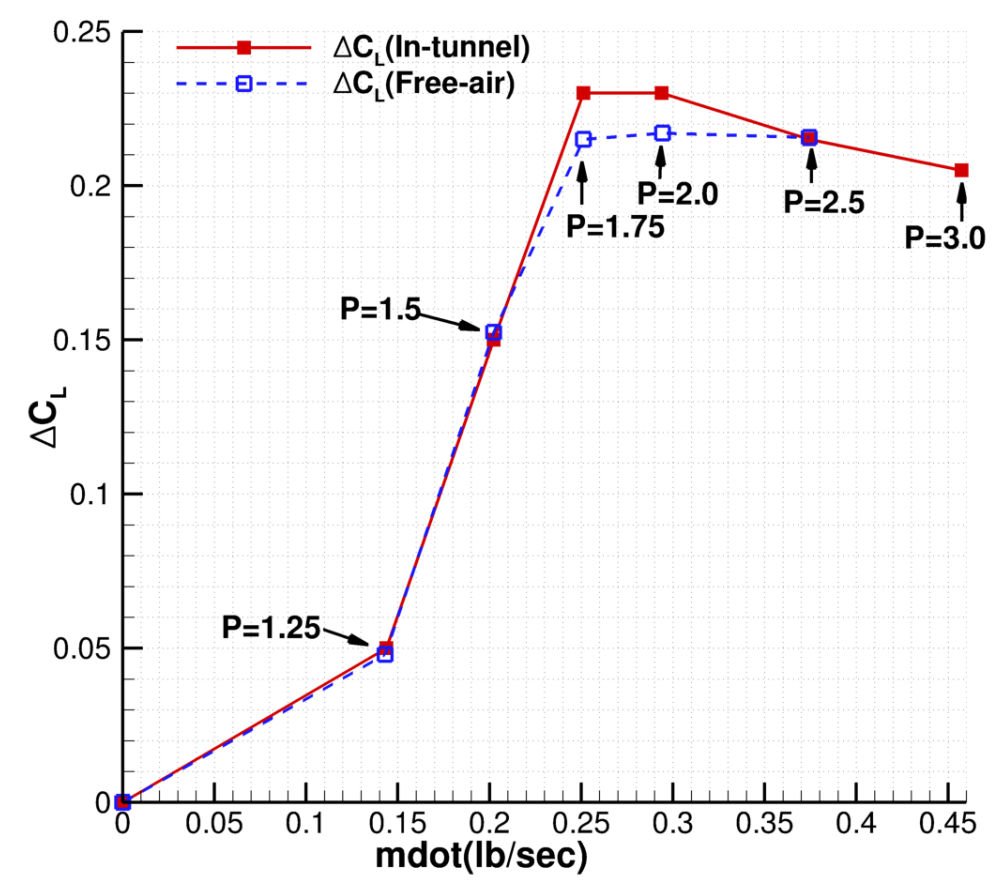

Figure 14. Effect of input mass flow variation on lift coefficient. 


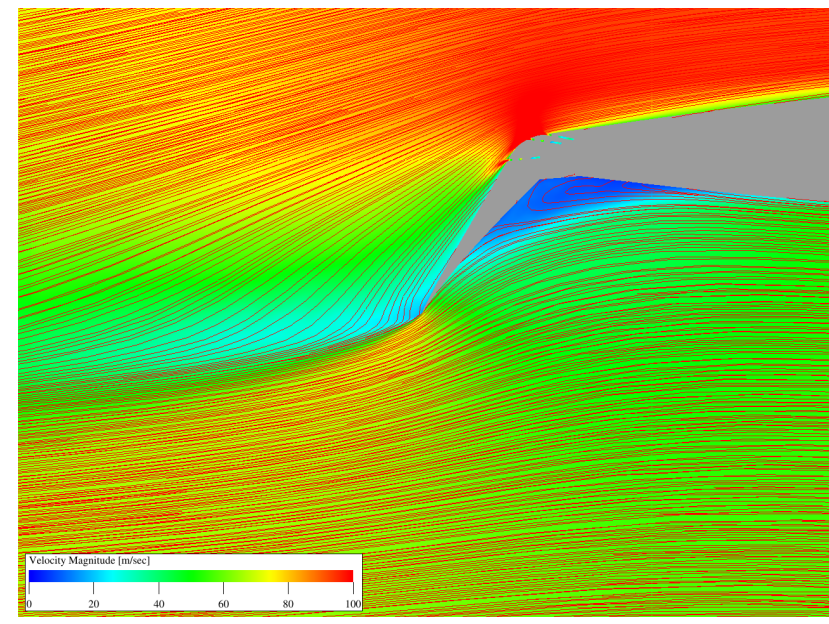

(a) In-tunnel: $\mathbf{P}=\mathbf{2 . 0}$

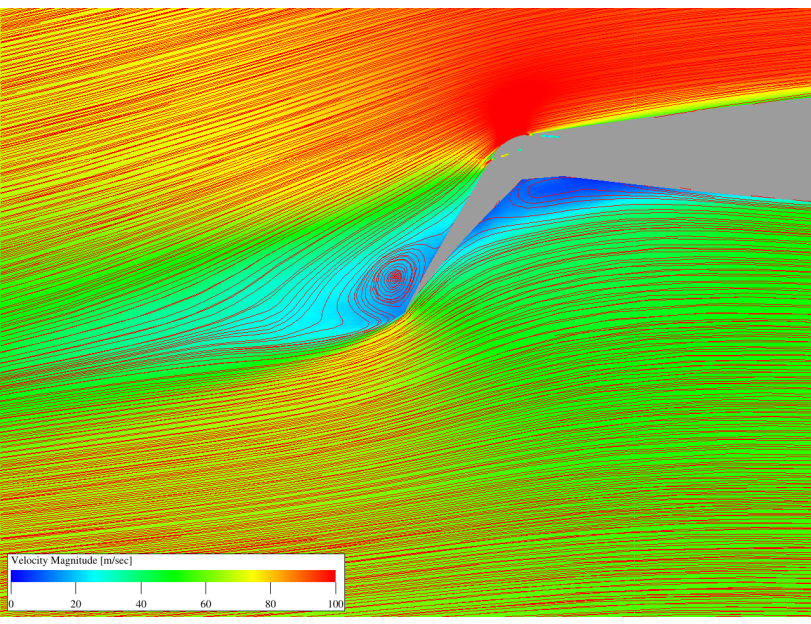

(b) Free-air: $\mathbf{P}=\mathbf{2 . 0}$

Figure 15. Effect of tunnel blockage on simulated streamline patterns, $y=27.75$ in.

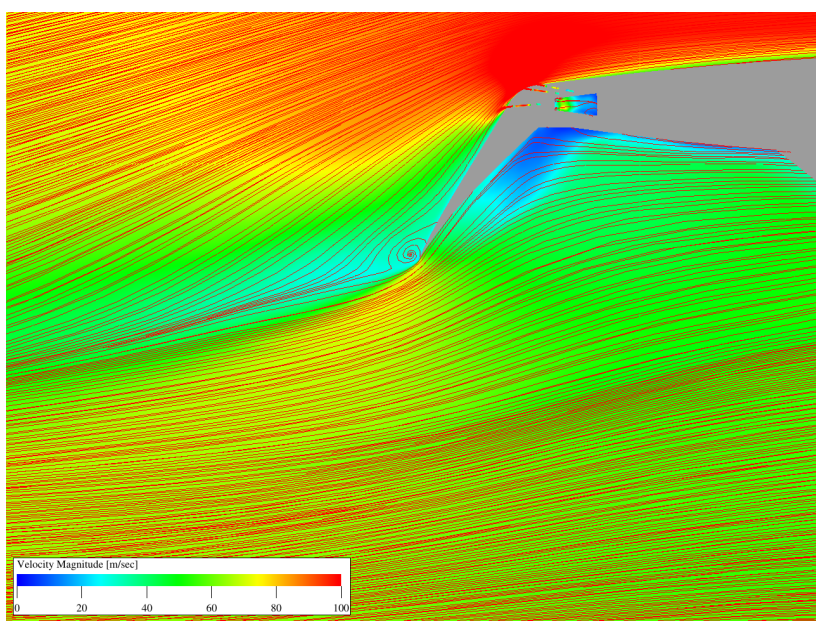

(a) In-tunnel: $\mathbf{P}=\mathbf{2 . 0}$

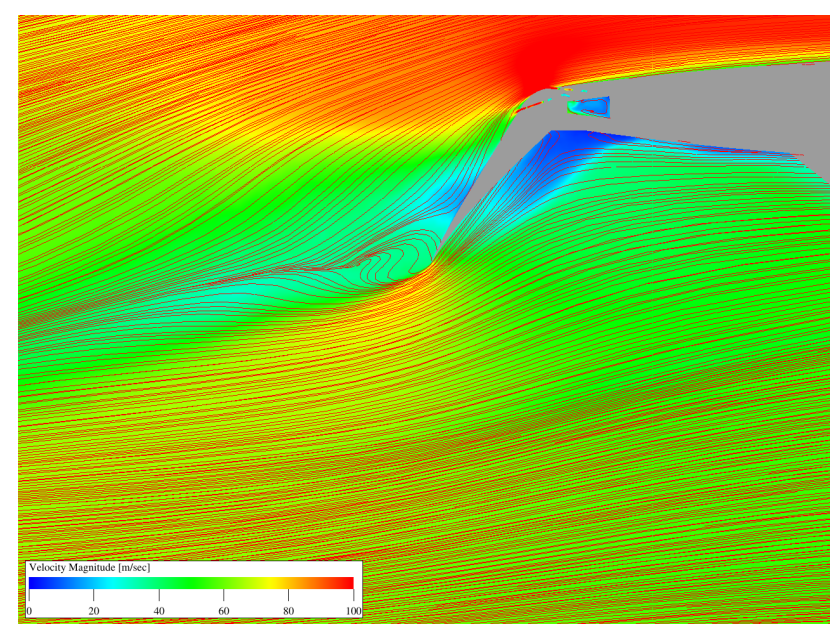

(b) Free-air: $\mathbf{P}=\mathbf{2 . 0}$

Figure 16. Effect of tunnel blockage on simulated streamline patterns, $y=38.05$ in. 


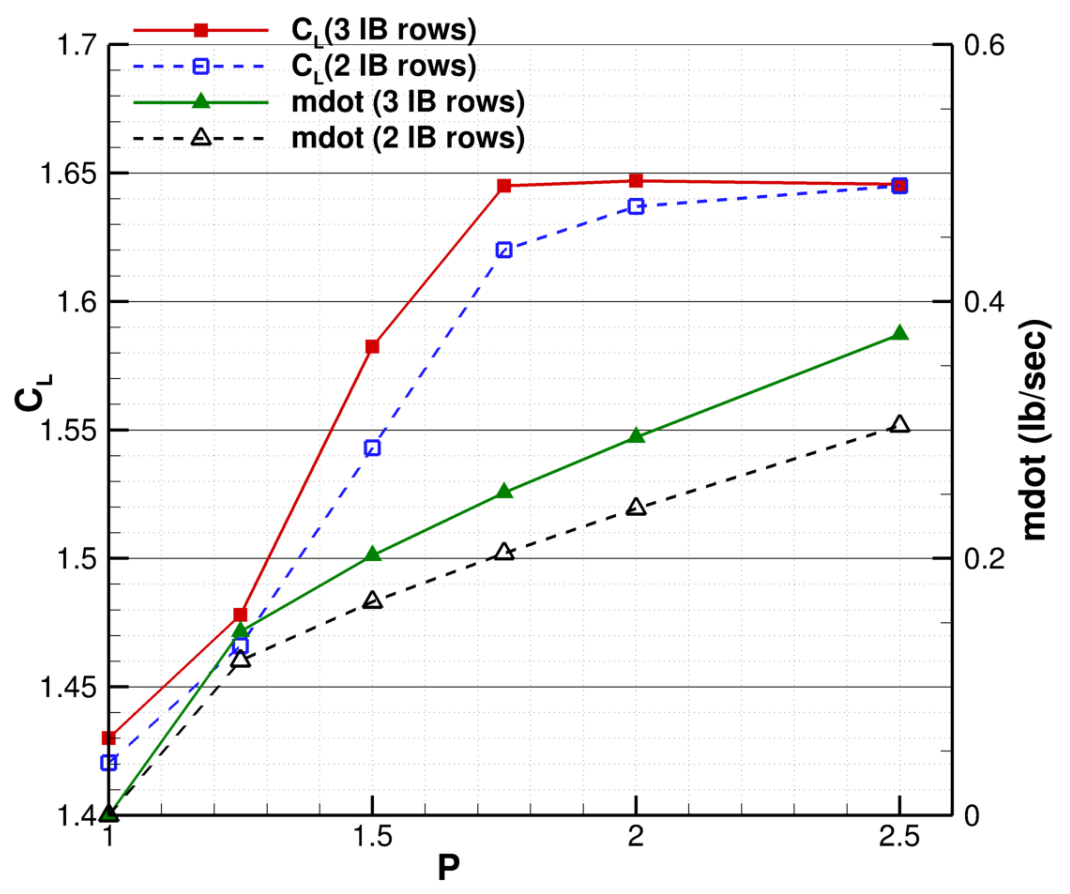

Figure 17. Effect of eliminating inboard middle row of actuators on lift coefficient and mass flow.

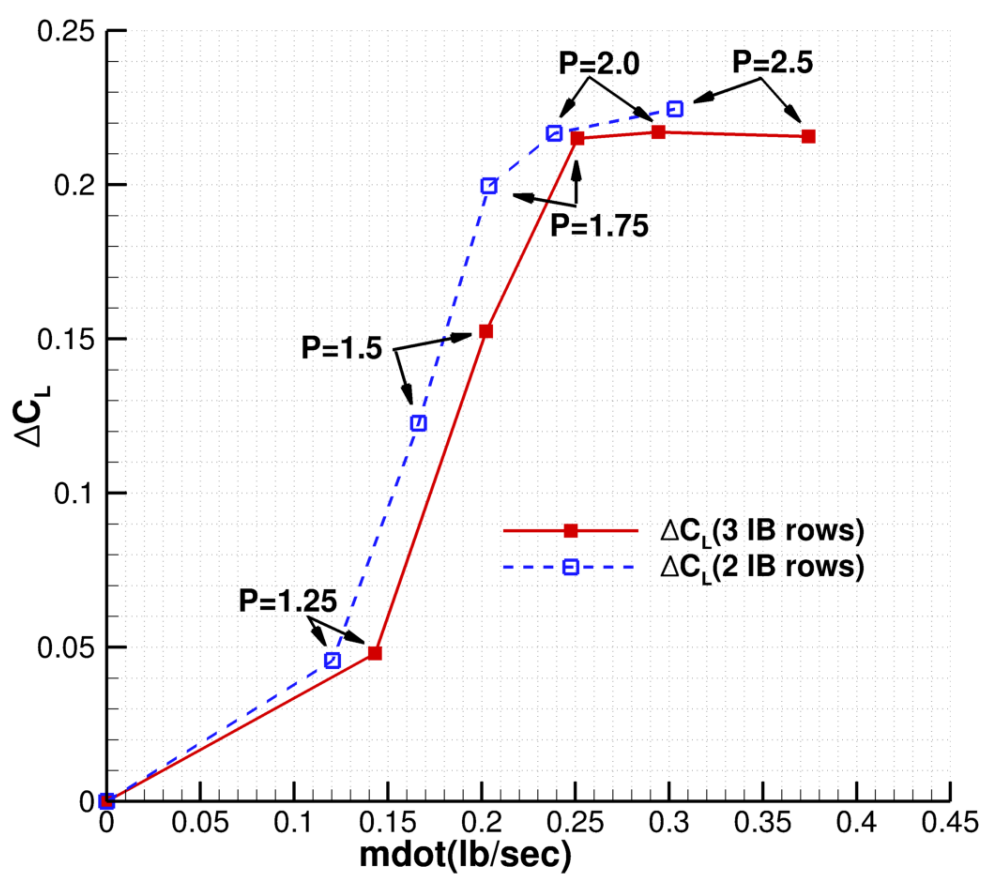

Figure 18. Effect of eliminating inboard middle row of actuators on lift increment. 


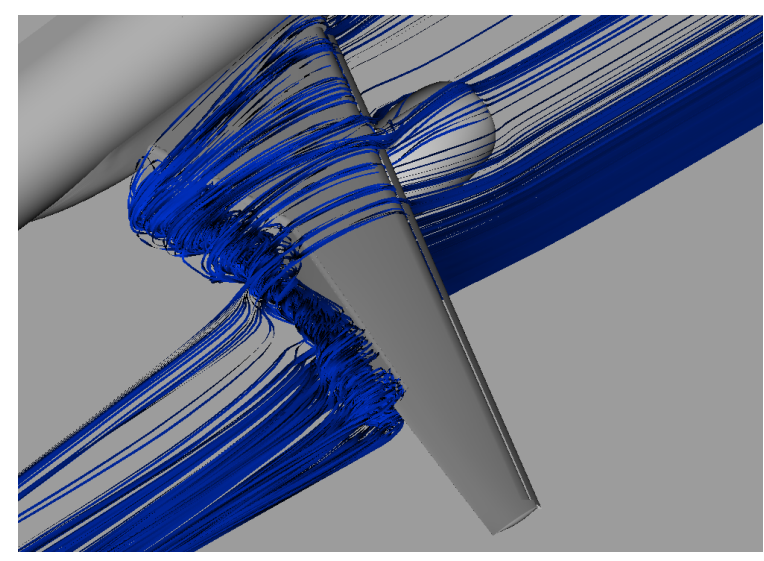

(a) 3-D streamlines

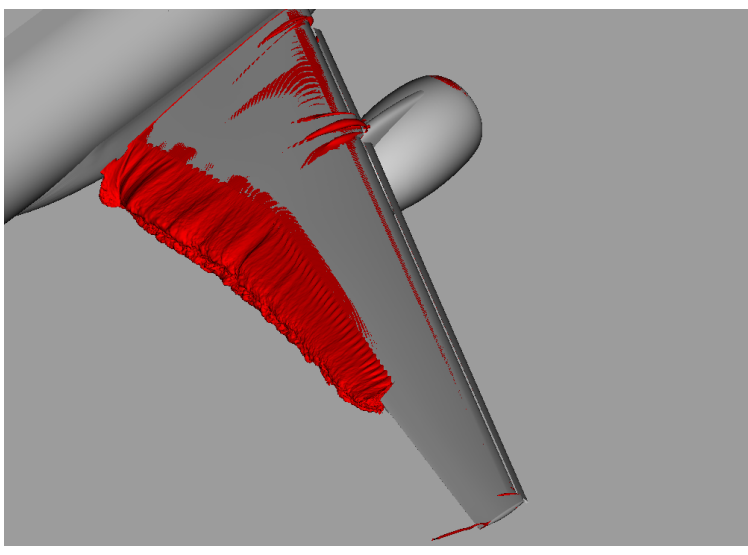

(b) Isosurface, $C_{p t}=-\mathbf{0 . 3 5}$

Figure 19. Effect of actuation on simulated surface streamline patterns, No AFC.

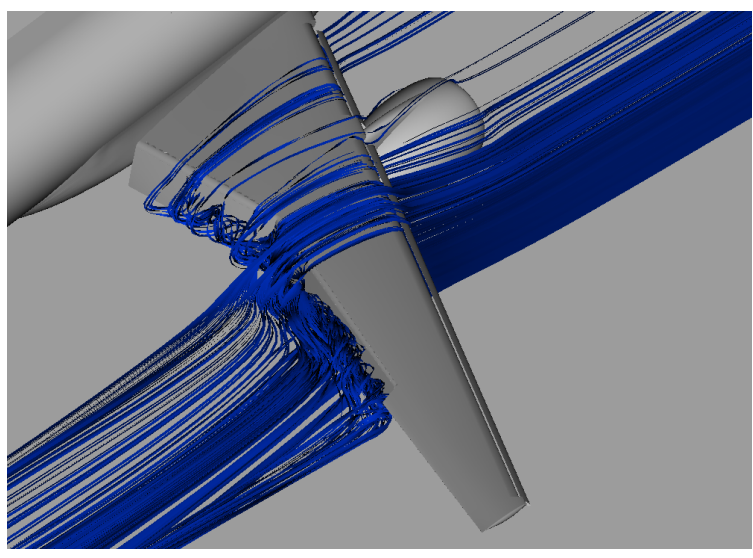

(a) 3-D streamlines

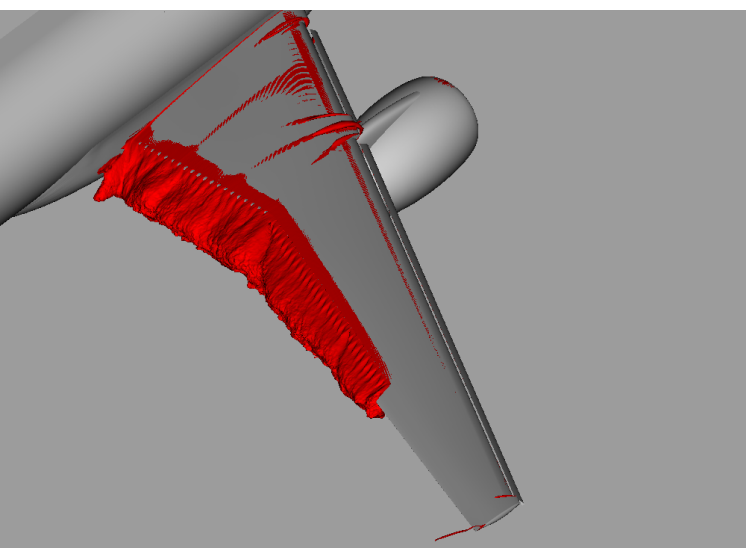

(b) Isosurface, $C_{p t}=-\mathbf{0 . 3 5}$

Figure 20. Effect of actuation on simulated surface streamline patterns, $P=1.25$. 


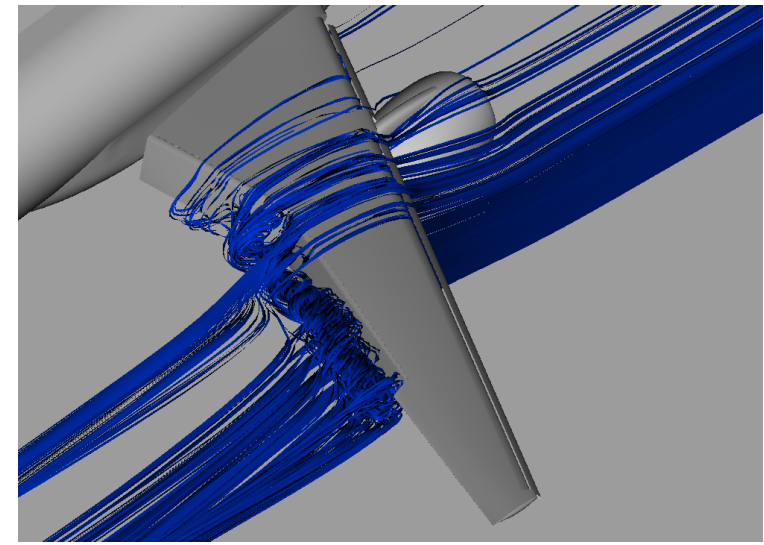

(a) 3-D streamlines

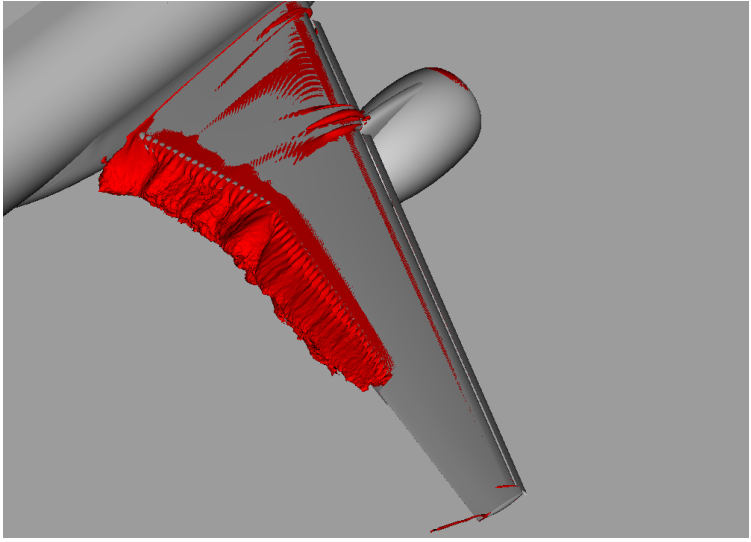

(b) Isosurface, $C_{p t}=-\mathbf{0 . 3 5}$

Figure 21. Effect of actuation on simulated surface streamline patterns, $P=1.5$.

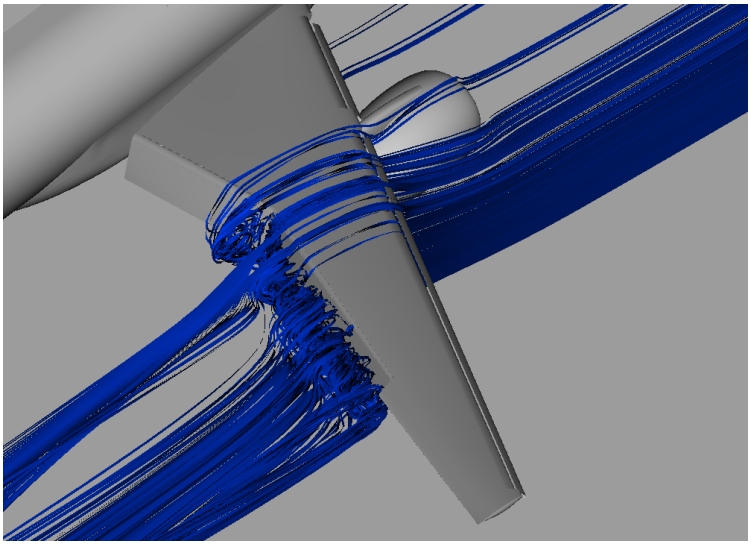

(a) 3-D streamlines

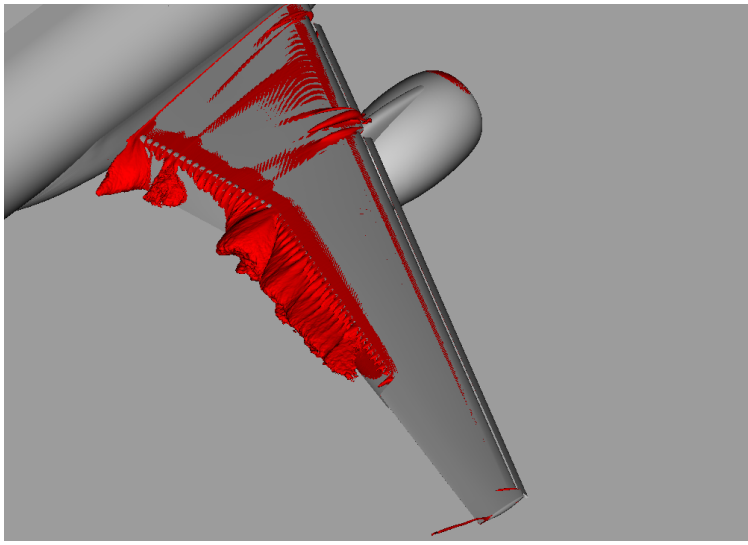

(b) Isosurface, $C_{p t}=-\mathbf{0 . 3 5}$

Figure 22. Effect of actuation on simulated surface streamline patterns, $P=1.75$.

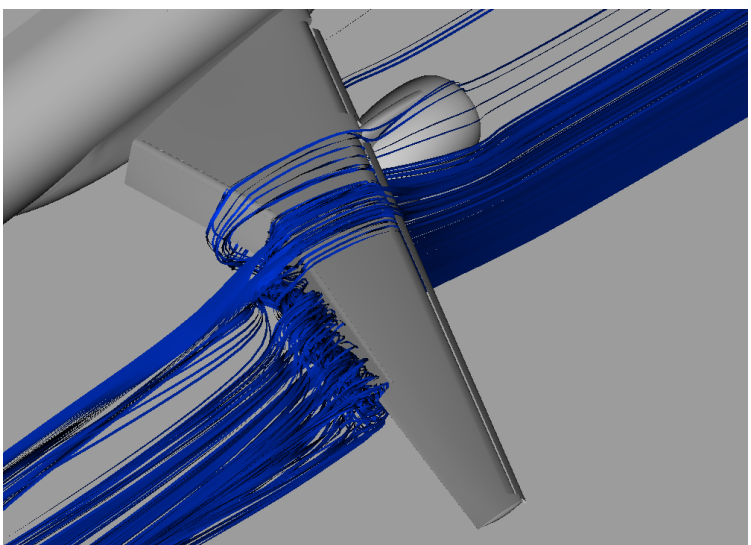

(a) 3-D streamlines

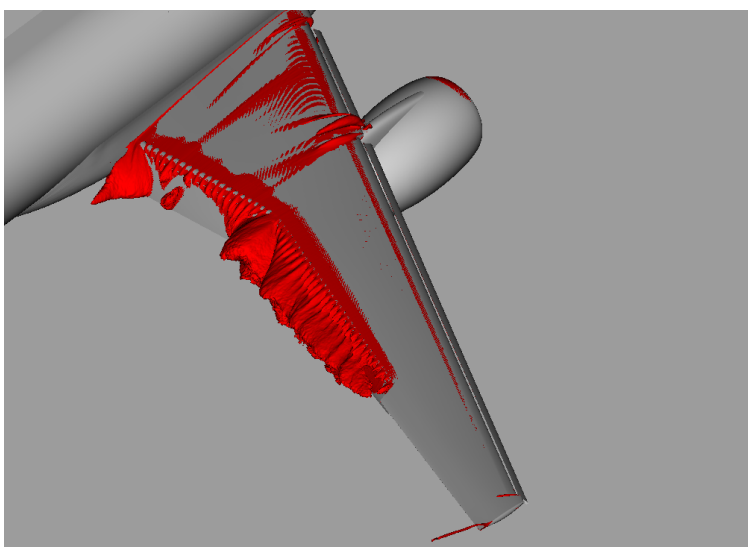

(b) Isosurface, $C_{p t}=-\mathbf{0 . 3 5}$

Figure 23. Effect of actuation on simulated surface streamline patterns, $P=2.0$. 